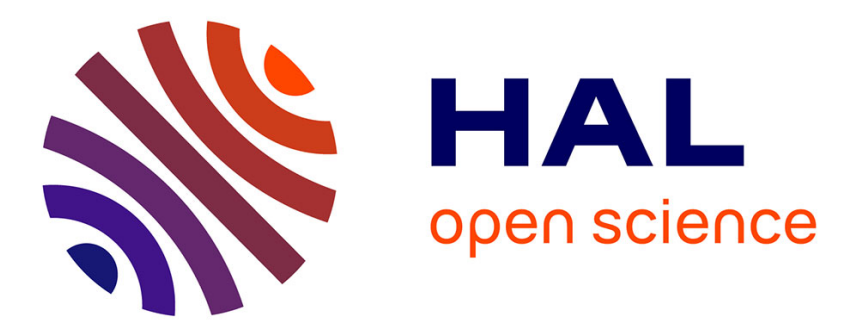

\title{
Hybrid photoanodes for water oxidation combining a molecular photosensitizer with a metal oxide oxygen-evolving catalyst
}

Marie-Noëlle Collomb, Daniela V Morales, Catalina N Astudillo, Baptiste Dautreppe, Jérôme Fortage

\section{To cite this version:}

Marie-Noëlle Collomb, Daniela V Morales, Catalina N Astudillo, Baptiste Dautreppe, Jérôme Fortage. Hybrid photoanodes for water oxidation combining a molecular photosensitizer with a metal oxide oxygen-evolving catalyst. Sustainable Energy \& Fuels, 2020, 4 (1), pp.31 - 49. 10.1039/C9SE00597H . hal-02366512

\section{HAL Id: hal-02366512 \\ https://hal.science/hal-02366512}

Submitted on 9 Nov 2020

HAL is a multi-disciplinary open access archive for the deposit and dissemination of scientific research documents, whether they are published or not. The documents may come from teaching and research institutions in France or abroad, or from public or private research centers.
L'archive ouverte pluridisciplinaire HAL, est destinée au dépôt et à la diffusion de documents scientifiques de niveau recherche, publiés ou non, émanant des établissements d'enseignement et de recherche français ou étrangers, des laboratoires publics ou privés. 


\section{Hybrid photoanodes for water oxidation combining a molecular photosensitizer to a metal oxide oxygen-evolving catalyst}

Received 00th January 20xx, Accepted 00th January 20xx

DOI: $10.1039 / x 0 x \times 00000 x$

www.rsc.org/

\author{
Marie-Noëlle Collomb, ${ }^{\text {a }}$ Daniela V. Morales, ${ }^{a}$ Catalina N. Astudillo, ${ }^{a}$ Baptiste Dautreppe ${ }^{a, b}$ and \\ Jérôme Fortage $*^{\mathrm{a}}$
}

\section{Introduction}

Light-driven water splitting into molecular hydrogen and oxygen is the subject of extensive research since it is considered as a sustainable way to produce the "clean" fuel hydrogen, one of the best alternatives to fossil fuels. ${ }^{1-15}$ Since the pioneer work of Fujishima and Honda ${ }^{16}$ in the early $70^{\prime}$ s, demonstrating photoelectrochemical water splitting by a $\mathrm{TiO}_{2}$ photoanode and a $\mathrm{Pt}$ counter electrode under UV light, the construction of photoelectrochemical cells (PEC) to perform the light-driven water splitting is extensively explored. ${ }^{13}$ Three main configurations of water-splitting PEC were reported which have been extensively discussed in several reviews ${ }^{1,2,6,7,17,18}$ : (i) cells where the two compartments containing respectively the photoanode for water oxidation into oxygen (oxygen evolving reaction, denoted OER) and the photocathode for water reduction into hydrogen (hydrogen evolving reaction, denoted HER) are separated by a membrane or a frit (the two photoelectrodes being connected by a wire), (ii) cells where the photoanode and the photocathode are joined back to back via an ohmic contact, delimiting the boundary between the two compartments (i.e. a wireless design), and (iii) cells where either a $\mathrm{p}$-n semiconductor junction layer is introduced between a photoanode and a cathode or two $p$-n junction layers are arranged in series between an anode and a cathode (respectively denoted photoanode/photovoltaic (PV)-PEC and dual PV-PEC). Among these configurations, tandem PECs combining two photoelectrodes are every attractive since they have the advantage of absorbing over a wide range of wavelengths of the visible spectrum and thus of presenting a realistic theoretical solar-to-hydrogen (STH)

\footnotetext{
a. Univ. Grenoble Alpes, CNRS, DCM, 38000 Grenoble, France.

${ }^{b .}$ Univ. Grenoble Alpes, CNRS, CEA, IRIG, SyMMES, 38000 Grenoble, France
}

conversion efficiency in the order of $15 \%$, 2,19 (provided that the photosensitive material of each photoelectrode absorbs in wavelength domains that are different from each other and complementary). In practice and to simplify their study, photoanodes and photocathodes are often optimized separately and investigated along with a simple platinum counter electrode, requiring therefore the supply of electricity (i.e. a bias) to operate.

Intense researches are devoted to the development of photoelectrodes solely based on inorganic semiconductor (SC) materials, ${ }^{2,7,11,15}$ but they face the difficulty of having a SC that can both effectively absorb visible light and display conduction and valence bands (denoted $C B$ and $V B$, respectively) with adequate energy levels to catalyze OER for photoanodes and HER for photocathodes. Some PECs using SCs based on metal oxides $\left(\mathrm{WO}_{3}\right.$, $\mathrm{BiVO}_{4}, \mathrm{Fe}_{2} \mathrm{O}_{3}$ and $\left.\mathrm{CuBi}_{2} \mathrm{O}_{4}\right)^{4,7,20-24}$ or oxynitrides ( $\mathrm{TaON}, \mathrm{LaTiO}_{2} \mathrm{~N}$ and $\left.\mathrm{SrNbO}_{2} \mathrm{~N}\right)^{25-28}$ for the photoanodes, and on $p$-type chalcogenides $\left(\mathrm{CdTe}, \mathrm{Culn}_{1-x} \mathrm{Ga}_{x} \mathrm{Se}_{2}\right)^{29,30}$ or metal oxides $\left(p-\mathrm{Cu}_{2} \mathrm{O}\right)^{31-34}$ for the photocathodes, do operate under visible light. Nevertheless their STH conversion efficiency remains below $10 \%$, the threshold for commercial applications. A few of PECs using InP, GaAs/GalnP $\mathrm{P}_{2}$ and $\mathrm{AlGaAs} / \mathrm{Si}$ SCs can exceed $10 \%$ of STH conversion efficiency under visible irradiation, but they suffer from a poor stability and employ In and Ga which are rare and expensive metals. ${ }^{35-38}$

An alternative approach is to design hybrid systems by coupling to the SCs a molecular photosensitizer (denoted PS and also called dye) for visible light absorption, and an oxygen- and hydrogenevolving catalyst, to promote the OER or HER. ${ }^{4,9,10,12-14,39-42}$ This molecular approach for the construction of water splitting PEC cells (or dye-sensitized-PEC, denoted DS-PEC), is an emerging line of research inspired by the technology of photovoltaic cells (i.e. dyesensitized solar cells, denoted DSSC). ${ }^{43}$ Herein, the OER and HER catalysts, which can be inorganic metal-based nanoparticles (NPs) 
or molecular metal complexes, are either bound or co-adsorbed with the molecular PS on the SC surface. ${ }^{9,10,14,44,45}$ Within the water splitting process, the OER remains the bottleneck even catalyzed by such metal-based catalyst, due to its slow kinetics (i.e. with a high activation barrier) and its large anodic overpotential, and is still more challenging than the HER. ${ }^{45}$

In this review article, we will focus on the "hybrid photoanodes" which assemble a molecular PS to a metal oxide $\left(\mathrm{MO}_{\mathrm{x}}\right)$ OER catalyst. These hybrid photoelectrodes associate the great tunability of the photophysical and electronic properties of molecular photosensitizers with the high catalytic activity and stability of inorganic catalysts. Since the seminal paper by Mallouk and coworkers published in 2009, ${ }^{46}$ that reports a semi-conducting $\mathrm{TiO}_{2}$ electrode sensitized by a trisbipyridine ruthenium complex coupled to an iridium oxide catalyst, about fifteen examples have been reported. In addition to trisbipyridine ruthenium complexes, ${ }^{46-53}$ organic photosensitizers of the type polyheptazine, ${ }^{54-60}$ perylene, ${ }^{61-}$ $63 \pi$-conjugated naphthalene benzimidazole polymer ${ }^{64}$ and freebase porphyrin, ${ }^{51}$ have been employed in association with $\operatorname{IrO}_{x}$ or $\mathrm{CoO}_{x}$ OER catalysts. Basically, these hybrid photoanodes comprise a transparent doped semi-conducting electrode (Indium Thin Oxide (ITO) or Fluoride Thin oxide (FTO)) covered with a $n$-type SC such as $\mathrm{TiO}_{2}, \mathrm{SnO}_{2}$ or $\mathrm{WO}_{3}$ on which the molecular PS is adsorbed, generally in mono-layer, as well as the $\mathrm{MO}_{\mathrm{x}}$ (nano)particles deposited by a chemical or photoelectrochemical way.

The electrochemical potential diagram of such DS-PEC for water oxidation is schematized in Fig. 1, along with the redox potentials of SCs and organic polymers and those of molecular photosensitizers at the ground and excited states. The light absorption by the dye molecule leads to an excited state (dye*), followed by a fast injection of the excited electron into the conduction band $(\mathrm{CB})$ of the nanostructured $n$-SC, that then migrates into its Fermi level, resulting in an oxidized dye $\left(\mathrm{dye}^{+}\right)$. In the absence of a photocathode within the DS-PEC, the application of a bias between the photoanode and the cathode (generally $\mathrm{Pt}$ ) is required in order to raise energetically the electrons injected into $n$-SC, so that they move towards the cathode via the external circuit to promote the reduction of protons to $\mathrm{H}_{2}$. If the lifetime of the charge separated state (dye $\mathrm{e}^{+} / \mathrm{e}^{-}$in $\mathrm{CB}$ of the $n$-SC) is sufficiently long, an electron transfer from the $\mathrm{MO}_{\mathrm{x}}$ nanoparticle catalyst to the oxidized dye occurs. Since the water oxidation requires four electrons, the catalyst needs to accumulate four holes in order to oxidize water. Catalytic water oxidation is typically slow (millisecond timescale) even catalyzed by oxide (nano)particles, and a major problem in such photoanode is the kinetic competition with the back electron transfer reactions which occur on a submillisecond time scale. Thus, low quantum yields for water splitting - typically $1-2 \%$ - are a consequence of the fast kinetics of charge recombination, which competes effectively with the catalytic oxidation of water. ${ }^{14}$ In this review article, the different hybrid photoanodes are described in function of the nature of the molecular dye. Hybrid photoanodes employing trisbipyridine ruthenium derivatives are described first, and then those using organic dyes are examined. The preparation of the photoanodes, the evaluation of their photocatalytic performance for OER, and the key factors that govern their efficiency and stability are highlighted. Table 1 summarizes the photocatalytic performance of these hybrid photoanodes.

\section{Hybrid photoanodes with a Ru-trisbipyridine derivative as photosensitizer}

The first example of hybrid photoanode using a ruthenium trisbipyridine derivative as photosensitizer was published by Mallouk and coworkers ${ }^{46}$ in 2009. This group designed a heteroleptic trisbipyridine ruthenium complex (denoted Ru1) with one bipyridine substituted by two phosphonate groups and another one by a bidentate carboxylic acid group (i.e. malonate) (Fig. 2).
(A)

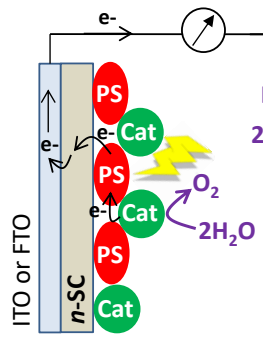

Photoanode

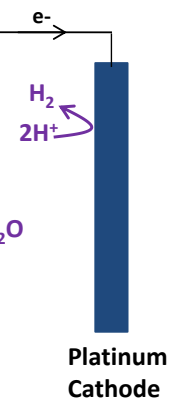

(B)

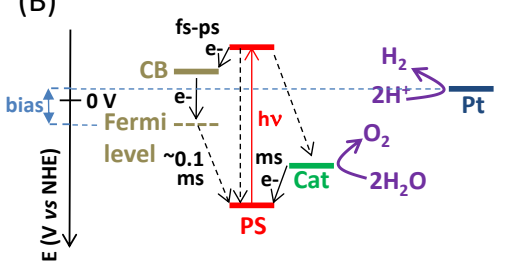

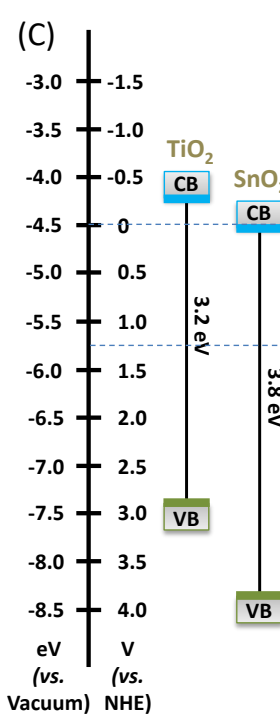

Fig. 1. Schematic representation (A) and electrochemical potential diagram (B) for a water-splitting DS-PEC based on a "hybrid photoanode" associating a molecular photosensitizer (PS) and a metal oxide (nano)particles OER catalyst (Cat) coupled to a Pt counter-electrode. The conduction band (CB) and the Fermi level of the $n$-type semiconducting electrode $(n-S C)$ are displayed. Solid and dashed lines represent respectively the forward and back electron transfers. (C) Potential diagram of $\mathrm{CB}$ and $\mathrm{CV}$ bands of $n$-type $\mathrm{SCS}\left(\mathrm{TiO}_{2}, \mathrm{SnO}_{2}, \mathrm{WO}_{3}\right.$ ) and organic polymers (polyheptazine ( $\mathrm{PH}$ ), poly[benzimidazobenzophenanthroline] $(\mathrm{BBL}))$, and oxidation potentials at the ground and excited states of molecular $\mathrm{PSs}$ : $\left.\mathrm{Ru}(\mathrm{bpy})_{3}{ }^{2+}\right)$, $\mathrm{N}, \mathrm{N}^{\prime}-$ bis(phosphonomethyl)-3,4,9,10-perylenediimide (PMPDI), (N,N'-Bis(2-(trimethylammonium)ethylene) perylene 3,4,9,10-tetracarboxylic acid diimide (PDI$\mathrm{N}^{+}$), 10-[2-(4-carboxyphenyl)ethenyl]-5,15-bis(2,4,6-trimethylphenyl)porphyrin (DMEP)). The dotted lines represent the thermodynamic potentials for

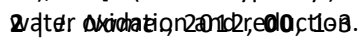
This journal is (C) The Royal Society of Chemistry 20xx 
Table 1. Summary of photocatalytic OER performance of DS-PECs using hybrid photoanodes which combines a molecular dye and a $\mathrm{MO}_{\mathrm{x}}$ catalyst

\begin{tabular}{|c|c|c|c|c|}
\hline Entry & $\begin{array}{l}\text { Substrate/SC/Sensitizer/OER } \\
\text { catalyst }^{a^{a}} \\
\text { Mode of adsorption of the } \\
\text { sensitizer and catalyst }\end{array}$ & $\begin{array}{l}\text { Steady-state photocurrent, applied bias }{ }^{\mathrm{b}} \\
\text { Stability } \\
\text { Experimental conditions }\end{array}$ & $\begin{array}{l}\text { Faradaic } \\
\text { efficiency } \\
\text { for OER }\end{array}$ & $\begin{array}{c}\text { Corresponding } \\
\text { Authors }^{\text {Ref }}\end{array}$ \\
\hline 1 & $\begin{array}{c}\mathrm{FTO} / \mathrm{TiO}_{2} / \mathbf{R u} 1-\mathrm{IrO}_{x} \cdot \mathrm{nH}_{2} \mathrm{O} \\
\text { Ru1-IrO } \mathrm{rO}_{x} \text { assembly deposited }\end{array}$ & $\begin{array}{c}\text { 10-30 } \mu \mathrm{A} \mathrm{cm}{ }^{-2} \text { at } 0 \mathrm{~V} \text { vs } \mathrm{Ag} / \mathrm{AgCl}(0.55 \mathrm{~V} \text { vs } \mathrm{RHE}) \\
\text { Stability: decayed over a period of } 4 \mathrm{~h} \\
\text { Aqueous } \mathrm{Na}_{2} \mathrm{SiF}_{6}-\mathrm{NaHCO}_{3} \text { buffer }(\mathrm{pH} 5.75), \text { Xe lamp }(>410 \mathrm{~nm})\end{array}$ & $20 \%$ & Mallouk $^{46}$ \\
\hline 2 & $\begin{array}{l}\mathrm{FTO} / \mathrm{TiO}_{2} / \mathrm{ZrO}_{2} / \mathrm{Ru} 1-\mathrm{IrO}_{\mathrm{x}} \cdot \mathrm{nH}_{2} \mathrm{O} \\
\text { Ru1-IrO } \\
\text { assembly deposited }\end{array}$ & $\begin{array}{c}40-50 \mu \mathrm{A} \mathrm{cm}{ }^{-2} \text { at } 0 \mathrm{~V} v \mathrm{Ag} / \mathrm{AgCl}(0.55 \mathrm{~V} \text { vs } \mathrm{RHE}) \\
\text { Stability: decrease within } 40 \mathrm{~s} \text { to stabilize at c. a. } 15 \mu \mathrm{A} \mathrm{cm} \\
\text { Aqueous } \mathrm{Na}_{2} \mathrm{SiF}_{6}-\mathrm{NaHCO}_{3} \text { buffer }(\mathrm{pH} 5.8), \text { Xe lamp }(150 \mathrm{~W},>410 \mathrm{~nm})\end{array}$ & $\approx 100 \%$ & Mallouk $^{47}$ \\
\hline 3 & $\begin{array}{c}\mathrm{FTO} / \mathrm{TiO}_{2} / \mathrm{Ru}_{2} / \mathrm{BIP}-\mathrm{IrO}_{\mathrm{x}} \cdot \mathrm{nH}_{2} \mathrm{O}-\mathrm{CEPA} \\
\text { Co-adsorbed with BIP mediator }\end{array}$ & 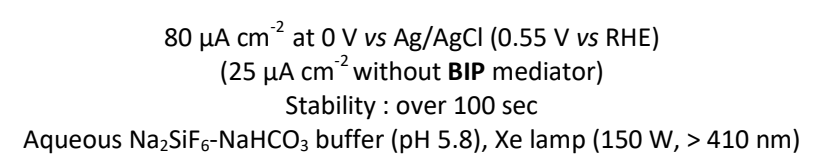 & $\begin{array}{l}85 \% \\
\text { (with or } \\
\text { without } \\
\text { BIP) }\end{array}$ & Mallouk $^{48}$ \\
\hline 4 & $\begin{array}{l}\mathrm{FTO} / \mathrm{TiO}_{2} / \mathrm{Ru} 3 / \mathrm{IrO}_{2} \text { sintered } \\
\text { successively deposited }\end{array}$ & $\begin{array}{c}80 \mu \mathrm{A} \mathrm{cm}^{-2} \text { at } 0.1 \mathrm{~V} \text { vs } \mathrm{Ag} / \mathrm{AgCl}(0.71 \mathrm{~V} \text { vs } \mathrm{RHE}) \\
\text { Stability : decrease to } 10 \mu \mathrm{A} \mathrm{cm}^{-2} \text { after } 600 \mathrm{~s} \\
\text { Phosphate buffer (pH 6.8), solar simulator (AM 1.5, > } 410 \mathrm{~nm})\end{array}$ & $98 \%$ & Mallouk $^{49,50}$ \\
\hline 5 & $\begin{array}{l}\mathrm{FTO} / \text { nanolTO} / \mathrm{TiO}_{2} / \mathrm{Ru} 4 / \mathrm{IrO}_{2} \\
\text { successively deposited } \\
\mathrm{FTO} / \text { nanolTO/TiO } / \text { Ru4 } / \mathrm{TiO}_{2} / \mathrm{IrO}_{2} \\
\text { successively deposited }\end{array}$ & 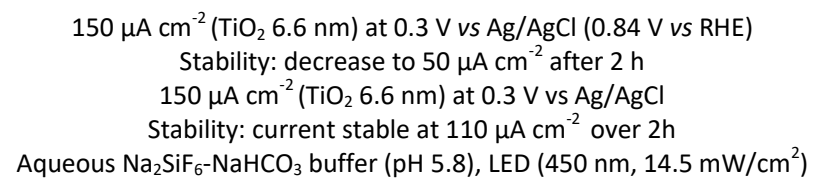 & $\begin{array}{c}\text { Not } \\
\text { determined }\end{array}$ & Murray $^{52}$ \\
\hline 6 & $\begin{array}{c}\mathrm{FTO} / \mathrm{TiO}_{2} / \mathrm{Ru} 5 / \mathrm{Co}_{3} \mathrm{O}_{4} \\
\text { successively deposited }\end{array}$ & $\begin{array}{c}135 \mu \mathrm{A} \mathrm{cm} \text { at } 0.3 \mathrm{~V} \text { vs } \mathrm{Ag} / \mathrm{AgCl}(0.90 \mathrm{~V} \text { vs } \mathrm{RHE}) \\
\qquad\left(15 \mu \mathrm{A} \mathrm{cm}^{-2} \text { without } \mathrm{Co}_{3} \mathrm{O}_{4}\right) \\
\text { Stability: decrease to } 50 \mu \mathrm{A} \mathrm{cm} \text { after } 3 \mathrm{cycles} \text { of } 20 \text { s illumination } \\
\text { Phosphate buffer (pH 6.8), Xe lamp }\left(100 \mathrm{~mW} / \mathrm{cm}^{2},>400 \mathrm{~nm}\right)\end{array}$ & $\begin{array}{c}\text { Not } \\
\text { determined }\end{array}$ & $\mathrm{Na}^{53}$ \\
\hline 7 & $\begin{array}{l}\text { ITO or } \mathrm{FTO} / \mathrm{TiO}_{2} / \mathrm{PH} / \mathrm{IrO}_{2} \\
\text { successively deposited }\end{array}$ & $\begin{array}{l}100 \mu \mathrm{A} \mathrm{cm}{ }^{-2} \text { at } 0.5 \mathrm{~V} \text { vs } \mathrm{Ag} / \mathrm{AgCl}(1.12 \mathrm{~V} \text { vs } \mathrm{RHE}) \\
\text { Stability: over } 90 \mathrm{~min} \\
\text { Phosphate buffer }(\mathrm{pH} 7), \text { Xe lamp }(150 \mathrm{~W},>420 \mathrm{~nm})\end{array}$ & $19 \%$ & Beranek $^{54,55}$ \\
\hline 8 & $\begin{array}{l}\text { ITO or } \mathrm{FTO} / \mathrm{TiO}_{2} / \mathrm{PH} / \mathrm{Co}-\mathrm{Pi} \\
\text { successively deposited } \\
\text { Co-Pi photoelectrochemically } \\
\text { deposited }\end{array}$ & $\begin{array}{c}190 \mu \mathrm{A} \mathrm{cm}^{-2} \text { at } 1.12 \mathrm{~V} \text { vs RHE } \\
\text { Phosphate buffer (pH 7.0), stability: decrease to } 40 \mu \mathrm{A} \mathrm{cm}{ }^{-2} \text { after } 1 \mathrm{~h} 30 \\
120 \mu \mathrm{A} \mathrm{cm}{ }^{-2} \text { at } 1.12 \mathrm{~V} \text { vs RHE } \\
\text { Borate buffer (pH 7.7), stability : decrease to } 40 \mu \mathrm{A} \mathrm{cm} \mathrm{cm}^{-2} \text { after } 2 \mathrm{~h} \\
\text { Xe lamp }(150 \mathrm{~W},>420 \mathrm{~nm})\end{array}$ & $17 \%$ & Beranek $^{60}$ \\
\hline 9 & $\begin{array}{l}\text { ITO or } \mathrm{FTO} / \mathrm{TiO}_{2} / \mathrm{PH} / \mathrm{CoO}(\mathrm{OH})_{x} \\
\text { successively deposited } \\
\mathrm{CoO}(\mathrm{OH})_{x} \text { chemically deposited }\end{array}$ & $\begin{array}{c}200 \mu \mathrm{A} \mathrm{cm}{ }^{-2} \text { at } 1.12 \mathrm{~V} \text { vs RHE } \\
\text { Phosphate buffer (pH 7.0), stability : decrease to } 40 \mu \mathrm{A} \mathrm{cm}{ }^{-2} \text { after } 2 \mathrm{~h} 30 \\
160 \mu \mathrm{A} \mathrm{cm} \mathrm{cm}^{-2} \text { at } 1.12 \mathrm{~V} \text { vs RHE } \\
\text { Borate buffer (pH 7.7), stability : decrease to } 110 \mu \mathrm{A} \mathrm{cm} \mathrm{cm}^{-2} \text { after } 4 \mathrm{~h} \\
\text { Xe lamp (> } 420 \mathrm{~nm} \text { ) }\end{array}$ & $34 \%$ & Beranek $^{60}$ \\
\hline 10 & $\begin{array}{c}\text { ITO/PMPDI/CoO } \\
\text { successively deposited } \\
\mathrm{CoO}_{\mathrm{x}} \text { photoelectrochemically } \\
\text { deposited }\end{array}$ & $\begin{array}{l}150 \mu \mathrm{A} \mathrm{cm}^{-2} \text { at } 1.0 \mathrm{~V} \text { vs } \mathrm{Ag} / \mathrm{AgCl}(1.61 \mathrm{~V} \text { vs RHE) }(\eta=0.38 \mathrm{~V}) \\
125 \mu \mathrm{A} \mathrm{cm}^{-2} \text { at } 0.9 \mathrm{~V} \text { vs } \mathrm{Ag} / \mathrm{AgCl}(1.51 \mathrm{~V} \text { vs RHE) }(\eta=0.28 \mathrm{~V}) \\
\text { Stability : decrease to } 100 \mu \mathrm{A} \mathrm{cm}{ }^{-2} \text { over } 300 \mathrm{~s} \text { at }+0.9 \mathrm{~V} \text { vs Ag/AgCl } \\
\text { Phosphate buffer (pH 7.0), Xe lamp }\left(100 \mathrm{~mW} / \mathrm{cm}^{2}, 315-710 \mathrm{~nm}\right)\end{array}$ & $\begin{array}{c}80 \pm 15 \% \\
\text { at }+0.9 \vee v s \\
\mathrm{Ag} / \mathrm{AgCl}\end{array}$ & Finke $^{61}$ \\
\hline 11 & $\begin{array}{l}\mathrm{FTO} / \mathrm{SnO}_{2} / \mathrm{PMPDI} / \mathrm{CoO}_{\mathrm{x}} \\
\text { successively deposited } \\
\mathrm{CoO}_{\mathrm{x}} \text { photoelectrochemically } \\
\text { deposited }\end{array}$ & 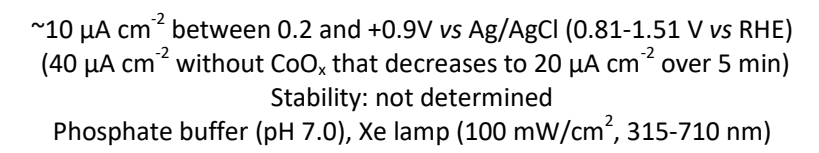 & $31 \pm 7 \%$ & Finke $^{62}$ \\
\hline 12 & $\begin{array}{l}\mathrm{FTO} / \mathrm{WO}_{3} / \mathrm{PDI}^{-\mathrm{N}^{+}} / \mathrm{IrO}_{2} \\
\text { co-deposited }\end{array}$ & $\begin{array}{c}70 \mu \mathrm{A} \mathrm{cm}^{-2} \text { at } 0.55 \mathrm{~V} \text { vs } \mathrm{Ag} / \mathrm{AgCl}(0.92 \mathrm{~V} \text { vs } \mathrm{RHE}) \\
\left(\sim 17 \mu \mathrm{A} \mathrm{cm}^{-2} \text { without } \mathrm{IrO}_{2}\right) \\
\text { Stability: not determined } \\
\left.\mathrm{H}_{2} \mathrm{O}(\mathrm{pH} 3.0) \text {, solar simulator (AM } 1.5,>435 \mathrm{~nm}\right)\end{array}$ & $\begin{array}{l}\text { Not } \\
\text { determined }\end{array}$ & Bignozzi $^{63}$ \\
\hline
\end{tabular}


13

$\mathrm{FTO} / \mathrm{BBL} / \mathrm{TiO}_{2} / \mathrm{Ni}-\mathrm{Co}$ successively deposited
$\mathrm{FTO} / \mathrm{TiO}_{2} / \mathrm{DMEP} / \mathrm{IrO}_{2}$ sintered successively deposited $\sim 30 \mu \mathrm{A} \mathrm{cm}{ }^{-2}$ between 0.85 and $1.4 \mathrm{~V}$ vs RHE

( 15-20 $\mu \mathrm{A} \mathrm{cm}^{-2}$ without Ni-Co)

Stability: not determined

$82 \pm 16 \%$

Sivula $^{64}$

$\sim 40 \mu \mathrm{A} \mathrm{cm}{ }^{-2}$ at $0.1 \mathrm{~V}$ vs $\mathrm{Ag} / \mathrm{AgCl}(0.71 \mathrm{~V}$ vs $\mathrm{RHE})$

Stability: decrease to $10 \mu \mathrm{A} \mathrm{cm}{ }^{-2}$ after $600 \mathrm{~s}$

Phosphate buffer (pH 6.8), solar simulator (AM 1.5, > $410 \mathrm{~nm}$ or $>\quad 102 \pm 5 \% \quad$ Mallouk $^{51}$ $590 \mathrm{~nm})$

\begin{abstract}
Ru1-5 = tris-bipyridine ruthenium complexes with various substituents on the bipyridine ligands; BIP = benzimidazole-phenol; CEPA = 2carboxyethylphosphonic acid; $\mathbf{P H}=$ Poly-heptazine $\left(\mathrm{g}-\mathrm{C}_{3} \mathrm{~N}_{4}\right)$; PMPDI = N,N'-bis(phosphonomethyl)-3,4,9,10-perylenediimide; PDI-N $\mathbf{N}^{+}=\left(\mathrm{N}, \mathrm{N}^{\prime}-\mathrm{Bis}(2-\right.$ (trimethylammonium)ethylene) perylene 3,4,9,10-tetracarboxylic acid diimide; $\mathbf{B B L}=$ poly[benzimidazobenzophenanthroline]; $\mathbf{D M E P}=10$-[2-(4carboxyphenyl)ethenyl]-5,15-bis(2,4,6-trimethylphenyl)porphyrin. ${ }^{\text {b }}$ Potential of the applied bias has been converted to the RHE reference electrode : $\mathrm{E}(\mathrm{V}$ vs $\mathrm{RHE})=\mathrm{E}(\mathrm{V}$ vs $\mathrm{Ag} / \mathrm{AgCl} 3 \mathrm{M} \mathrm{KCl} / \mathrm{NaCl})+0.210+0.0592 \times \mathrm{pH} ; \mathrm{E}(\mathrm{V}$ vs $\mathrm{RHE})=\mathrm{E}(\mathrm{V}$ vs Ag/AgCl sat $)+0.197+0.0592 \times \mathrm{pH} ; \mathrm{E}(\mathrm{V} v s \mathrm{RHE})=\mathrm{E}(\mathrm{V} v s \mathrm{SCE})+0.241+$ $0.0592 \times \mathrm{pH}$
\end{abstract}
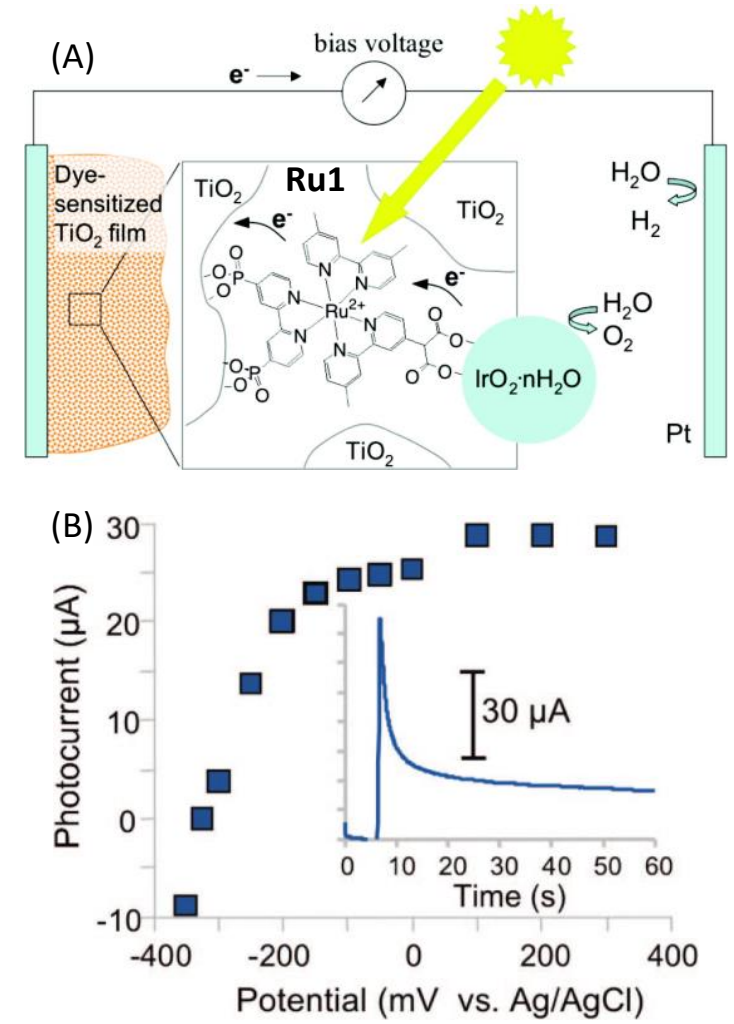

Fig. 2. (A) Schematic representation of water-splitting dye sensitized solar cell developed by Mallouk and coworkers ${ }^{46}$ based on a hybrid photoanode $\mathrm{FTO} / \mathrm{TiO}_{2} / \mathrm{Ru} 1-\mathrm{IrO}_{2} \cdot \mathrm{nH}_{2} \mathrm{O}$. (B) Corresponding steady-state photocurrent in function of the applied potential and transient photocurrent recorded at $0 \mathrm{~V}$ vs $\mathrm{Ag} / \mathrm{AgCl}$ in function of time (inset) in an aqueous buffered solution at $\mathrm{pH}$ 5.75 (reproduced from ref $^{46}$, with the permission from the American Chemical Society, Copyright 2009).

The phosphonate groups of the dye allow its adsorption onto porous nanocrystalline $\mathrm{TiO}_{2}$ semi-conductor (SC) while the malonate group links the dye to the hydrated iridium oxide nanoparticles $\mathrm{IrO}_{2} \cdot \mathrm{nH}_{2} \mathrm{O}$, that were used as efficient water oxidation catalysts. ${ }^{65}$ The Ru1- $/ \mathrm{rO}_{2} \cdot \mathrm{nH}_{2} \mathrm{O}$ assembly was first chemically synthetized from Ru1 and the $\mathrm{K}_{2} \mid \mathrm{ICl}_{6}$ salt in water, and then adsorbed onto $\mathrm{TiO}_{2}$. The malonate group of Ru1 acts as a stabilizer to control their size and polydispersity of the $\operatorname{IrO}_{2} \cdot \mathrm{nH}_{2} \mathrm{O}$ nanoparticles, resulting in well dispersed particles of $\sim 2 \mathrm{~nm}$ of diameter. The photoelectrochemical performances of the $\mathrm{FTO} / \mathrm{TiO}_{2} / \mathrm{Ru} 1-\mathrm{IrO}_{2} \cdot \mathrm{nH}_{2} \mathrm{O}$ photoanode was evaluated with a Pt wire as the counter electrode and a $\mathrm{Ag} / \mathrm{AgCl}$ reference electrode, immersed in an aqueous buffered solution at pH 5.75 (Fig. 2(A)). Irradiation of the photoanode with visible light $(\lambda>410 \mathrm{~nm})$ produced a measurable photocurrent at potentials more positive than $-325 \mathrm{mV}$ vs $\mathrm{Ag} / \mathrm{AgCl}$ (Fig. 2(B)). However, when a bias of $0 \mathrm{~V}$ vs $\mathrm{Ag} / \mathrm{AgCl}$ is applied, the observed anodic current spike decayed rapidly into a steady current (typically $10-30 \mu \mathrm{A} v s 1-2 \mu \mathrm{A}$ with unsensitized $\mathrm{TiO}_{2}$ ) (Fig. 2(B) and Table 1, Entry 1). Under steady illumination, the current decayed over a period of approximately 4 hours. The decay in photocurrent is coupled to a bleaching of the visible absorbance of the dye grafted on $\mathrm{TiO}_{2}$. A small bias to reach overall water splitting is needed in such system, because electrons in trap states below of the $\mathrm{TiO}_{2}$ conduction band edge are not enough reductive to generate $\mathrm{H}_{2}$ and rapidly recombine with holes located on the photo-oxidized dyes.

Finally, the photocurrent measured using $450 \mathrm{~nm}$ light at 7.8 $\mathrm{mW} \mathrm{cm}{ }^{-2}$ intensity of $12.7 \mu \mathrm{A} \mathrm{cm} \mathrm{cm}^{-2}$, corresponds to an internal quantum yield of $\sim 0.9 \%$. The production of hydrogen and oxygen was confirmed by gas chromatography and, in the case of oxygen, the amount of gas was also estimated by using a pseudo-clark electrode. The faradaic efficiency for the photoanodic oxygen generation was $\sim 20 \%$. After approximately $4 \mathrm{~h}$, the total photocurrent produced corresponds to a turnover of 16 per dye molecule. The low quantum yield was attributed to a slow electron transfer from the $\mathrm{IrO}_{2} \cdot \mathrm{nH}_{2} \mathrm{O}$ nanoparticles to the oxidized dye $(2.2$ $\mathrm{ms})$, which was measured as six times slower than the backelectron transfer $(0.37 \mathrm{~ms})$ from the trapped state of the $\mathrm{TiO}_{2} \mathrm{SC}$ to the photo-oxidized dye.

A strategy developed by the group of Mallouk to decrease the charge recombination was to introduce a thick insulating layer of $\mathrm{ZrO}_{2}$ or $\mathrm{Nb}_{2} \mathrm{O}_{5}(1-3 \mathrm{~nm})$ between the Ru photosensitizer and $\mathrm{TiO}_{2}{ }^{47}$ The core-shell FTO/TiO $/ 2 \mathrm{ZrO}_{2}$ and $\mathrm{FTO} / \mathrm{TiO}_{2} / \mathrm{Nb}_{2} \mathrm{O}_{5}$, were prepared by soaking the $\mathrm{FTO} / \mathrm{TiO}_{2}$ electrode in an alcohol solution of zirconium(IV) butoxide or niobium(V) chloride, washed with water and sintered at high temperature $\left(>400{ }^{\circ} \mathrm{C}\right)$. The Ru1- $\mathrm{IrO}_{2} \cdot \mathrm{nH}_{2} \mathrm{O}$ 
assembly was then chemisorbed on these core-shell electrodes by soaking. Transient absorption spectroscopy under open-circuit conditions revealed that the back electron transfer from $\mathrm{TiO}_{2}$ to oxidized Ru1 is faster within $\mathrm{TiO}_{2} / \mathrm{Ru} 1-\mathrm{IO}_{2} \cdot \mathrm{nH}_{2} \mathrm{O}$ than within $\mathrm{TiO}_{2} / \mathrm{ZrO}_{2} /$ Ru1- $-\mathrm{IOO}_{2} \cdot \mathrm{nH}_{2} \mathrm{O}$ and $\mathrm{TiO}_{2} / \mathrm{Nb}_{2} \mathrm{O}_{5} / \mathrm{Ru} 1-\mathrm{IrO}_{2} \cdot \mathrm{nH}_{2} \mathrm{O}$. The back electron transfer with $\mathrm{TiO}_{2} / \mathrm{Ru1}-\mathrm{IrO}_{2} \cdot \mathrm{nH}_{2} \mathrm{O}$ is multiphasic with two first-order decay times of $0.18 \mathrm{~ms} \mathrm{(42 \% )}$ and $0.01 \mathrm{~ms}$ (55\%). By contrast, the back electron transfer in presence of insulating layers of $\mathrm{ZrO}_{2}$ (2 layers) or $\mathrm{Nb}_{2} \mathrm{O}_{5}$ (1 layer) is monophasic and slower by a factor 2-3. The authors assume that the slower charge recombination in presence of $\mathrm{ZrO}_{2}$ and $\mathrm{Nb}_{2} \mathrm{O}_{5}$ layers occurs via the tunnel effect. This was also correlated to more negative potentials of the conduction bands of $\mathrm{ZrO}_{2}(-1.58 \mathrm{~V} \text { vs SCE })^{66,67}$ and $\mathrm{Nb}_{2} \mathrm{O}_{5}$ $(-0.84 \mathrm{~V})^{68}$ at $\mathrm{pH} 5.8$, compared to that of $\mathrm{TiO}_{2}(-0.76 \mathrm{~V}) .{ }^{69,70}$ As a direct consequence of the slower back electron transfer, the photocurrent at $-250 \mathrm{mV}$ vs $\mathrm{Ag} / \mathrm{AgCl}$ with the core-shell photoanodes ( 25 and $19 \mu \mathrm{A} \mathrm{cm}{ }^{-2} \mathrm{Nb}_{2} \mathrm{O}_{5}$ and $\mathrm{ZrO}_{2}$, respectively) is higher than that of photoanode without insulating layer $(14 \mu \mathrm{A}$ $\mathrm{cm}^{-2}$ ). Besides, with a bias of $0 \mathrm{~V}$ vs $\mathrm{Ag} / \mathrm{AgCl}$, the photocurrent of the core-shell photoanodes can reach $40-50 \mu \mathrm{A} \mathrm{cm}{ }^{-2}$ (Table 1, Entry 2). Nevertheless, this photocurrent decreases rapidly within $40 \mathrm{~s}$ to stabilize at $c a .15 \mu \mathrm{Am}^{-2}$, a value similar to that obtained with the $\mathrm{FTO} / \mathrm{TiO}_{2} / \mathrm{Ru} 1-\mathrm{IrO}_{2} \cdot \mathrm{nH}_{2} \mathrm{O}$ photoanodes without insulating layers. ${ }^{46}$ Since the fast degradation of the ruthenium dye was ruled out, the authors ascribed this photocurrent decay to the presence of protons generated by water oxidation that induces a positive shift of the water oxidation potential and then a decrease of its driving force. This study highlights that high and stable catalytic photocurrents could be obtained if the accumulation of protons on the electrode surface is reduced or even suppressed.

Another approach adopted by the group of Mallouk ${ }^{48}$ to improve the performance of such $\mathrm{Ru} / \mathrm{IrO}_{2}$ photoanodes was to incorporate an electron transfer mediator between the $\operatorname{IrO}_{x}$ nanoparticles and the ruthenium dye ${ }^{47}$ mimicking the tyrosinehistidine pair present in photosystem II (Fig. 3(A)). ${ }^{71}$ To achieve the structure, colloidal $\mathrm{IrO}_{\mathrm{x}} \cdot \mathrm{nH}_{2} \mathrm{O}$ nanoparticles were first bound to the benzimidazole-phenol (BIP) electron mediator and to 2carboxyethylphosphonic acid (CEPA) which is also used as anchoring molecule onto the $\mathrm{TiO}_{2}$ electrode. Characterization by UV-visible spectroscopy of CEPA capped $\mathrm{IrO}_{x} \cdot \mathrm{nH}_{2} \mathrm{O}$ without $\left(1-\mathrm{IrO}_{x} \cdot \mathrm{nH}_{2} \mathrm{O}\right)$ and with the BIP electron mediator $\left(2-\mathrm{IrO}_{\mathrm{x}} \cdot \mathrm{nH}_{2} \mathrm{O}\right)$, showed a broad absorbance at $580 \mathrm{~nm}$ typical of $\mathrm{Ir}(\mathrm{IV})$ oxide nanoparticles signature. For both $1-\mathrm{IrO}_{\mathrm{x}} \cdot \mathrm{nH}_{2} \mathrm{O}$ and $2-\mathrm{IrO}_{\mathrm{x}} \cdot \mathrm{nH}_{2} \mathrm{O}$, irregular nanoparticles of $2 \mathrm{~nm}$ were observed by TEM. The functionalized $\mathrm{IrO}_{\mathrm{x}}$ nanoparticles with and without BIP were then co-adsorbed on $\mathrm{TiO}_{2}$ with the ruthenium photosensitizer containing three bipyridine ligands substituted by one phenyl phosphonate group (Ru2) (Fig. $3(A)$ ). Different molar ratios of sensitizer and catalyst were investigated and the highest photocurrents were obtained with a 1:5 ratio of $\mathrm{Ru2}: \mathrm{IO}_{\mathrm{x}} \cdot \mathrm{nH}_{2} \mathrm{O}$ with and without BIP. In such conditions, at $\mathrm{pH} 5.8$ and for a bias at $0 \mathrm{~V} v \mathrm{Ag} / \mathrm{AgCl}$ (overpotential ( $\eta$ ) of -0.69 $\mathrm{V})$, the steady-state photocurrent density reaches up to $80 \mu \mathrm{A} \mathrm{cm}$ in the presence of the BIP mediator, with a stability over $100 \mathrm{~s}$ (Fig.
3(B) and Table 1, Entry 3). In the absence of mediator, a photocurrent of only $25 \mu \mathrm{A} \mathrm{cm}{ }^{-2}$ was obtained (thus around three times lower), a comparable value to that previously obtained with the heteroleptic Ru1 dye. ${ }^{46}$ In addition, without BIP, the photocurrent is less stable. This result is in agreement with faster electron transfer between the $\operatorname{IrO}_{x} \cdot \mathrm{nH}_{2} \mathrm{O}$ nanoparticles and $\mathbf{R u 2}$ when the catalyst nanoparticles are covered by the BIP mediator. Finally, the steady state photocurrent densities measured using 450 $\mathrm{nm}$ of light at $4.5 \mathrm{~mW} \mathrm{~cm}^{-2}$ of intensity, were respectively 29.1 and $10.1 \mu \mathrm{A} \mathrm{cm}^{-2}$ with and without mediator, corresponding to $2.3 \%$ and $0.8 \%$ of internal quantum yield, respectively. Thus, the quantum yield has been enhanced by more than a double, in the presence of the redox mediator. A faradaic efficiency for oxygen evolution superior to $85 \%$ was obtained by Clark electrode measurements for both $1-\mathrm{IrO}_{x} \cdot \mathrm{nH}_{2} \mathrm{O}$ and $2-\mathrm{IrO}_{x} \cdot \mathrm{nH}_{2} \mathrm{O}$. One drawback of the coadsorption is the absence of control of the juxtaposition of the photosensitizer and BIP-catalyst onto the $\mathrm{TiO}_{2}$ surface (Fig. 3(A)). The electron transfer rate between the BIP mediator and Ru2 dye is thus not well controlled, due to the fact that both molecules were separately adsorbed onto the $\mathrm{TiO}_{2}$ electrode surface. ${ }^{48}$
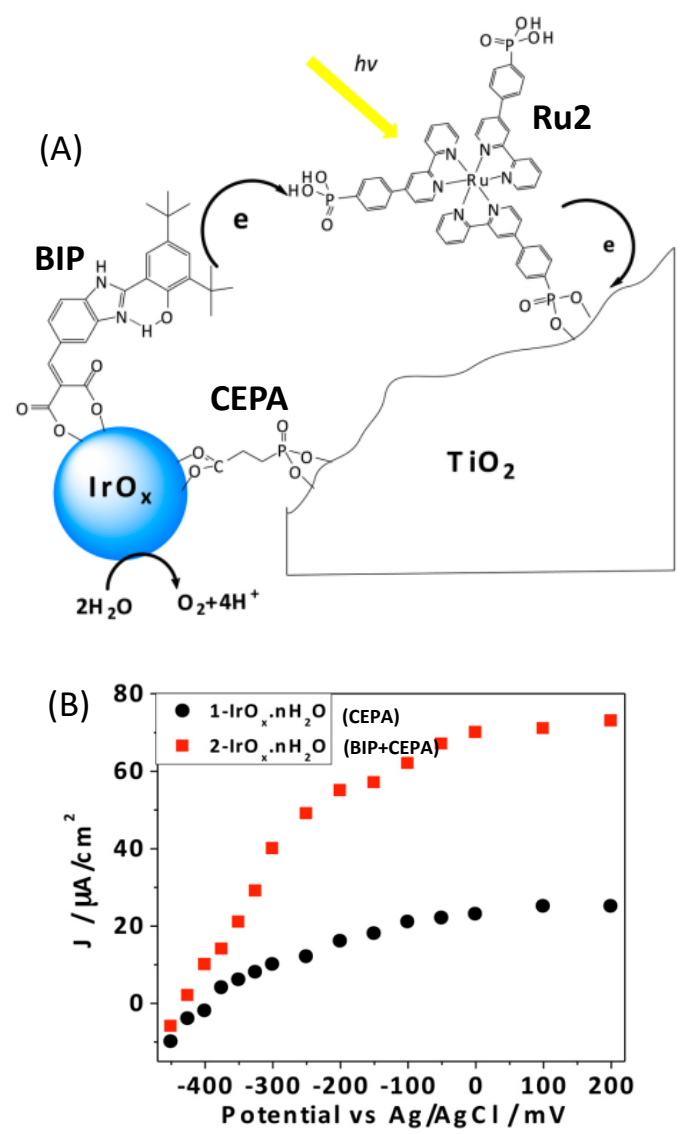

Fig. 3. (A) Schematic representation of the electron transfer reactions in the mediator-based, dye-sensitized $\mathrm{FTO} / \mathrm{TiO}_{2}$ photoanode developed by Mallouk and coworkers ${ }^{48}$ showing the molecular structures of Benzimidazole-phenol (BIP) mediator, Ru2 dye and 2-carboxyethylphosphonic acid (CEPA) anchoring group. (B) Corresponding steady-state photocurrent density in function of the anode potential for co-adsorbed $\mathbf{R u} 2$ and 1- $\mathrm{IrO}_{\mathrm{x}} \cdot \mathrm{nH}_{2} \mathrm{O}$ (CEPAcapped $\mathrm{IrO}_{\mathrm{x}}$ ) or 2- $\mathrm{IrO}_{\mathrm{x}} \cdot \mathrm{nH}_{2} \mathrm{O}$ (BIP- and CEPA-capped $\left(\mathrm{rO}_{\mathrm{x}}\right.$ ) in an aqueous buffered solution at $\mathrm{pH} 5.8$ (reproduced from ref $^{48}$, with the permission 
from the National Academy of Sciences of the United states of America, Copyright 2012).

Another approach investigated by Mallouk and coworkers ${ }^{49,50,72}$ was to sinter crystalline $\mathrm{IrO}_{2}$ nanoparticles $(2 \mathrm{~nm}$ ) directly onto the porous $\mathrm{TiO}_{2}$ film, instead of using amorphous $\mathrm{IrO}_{x}$ nanoparticles with capping ligands. The rutile $\mathrm{IrO}_{2}$ nanoparticles were deposited by soaking $\mathrm{FTO} / \mathrm{TiO}_{2}$ electrodes in a solution of colloidal $\mathrm{IrO}_{\mathrm{x}}$ capped with citrate, followed by a treatment at $450^{\circ} \mathrm{C}$. Rutile $\mathrm{IrO}_{2}$ is known to exhibit a higher catalytic activity per Ir atom than amorphous $\mathrm{IrO}_{\mathrm{x}}$. Then, the $\mathrm{Ru}$ photosensitizer comprising one bipyridine functionalized by two phosphonate anchoring groups (denoted Ru3), is grafted on the $\mathrm{FTO} / \mathrm{TiO}_{2} / \mathrm{IrO}_{2}$ electrode by soaking at room temperature (Fig. 4). The $\mathrm{FTO} / \mathrm{TiO}_{2} / \mathrm{Ru} 3 / \mathrm{IrO}_{2}$ photoanode displayed an anodic photocurrent spike of $225 \mu \mathrm{A} \mathrm{cm}{ }^{-2}$ with a bias of $0.1 \mathrm{~V} v \mathrm{~s}$ $\mathrm{Ag} / \mathrm{AgCl}$ that rapidly decayed to $80 \mu \mathrm{A} \mathrm{cm}{ }^{-2}$ after $30 \mathrm{~s}$ and then to 10 $\mu \mathrm{A} \mathrm{cm}{ }^{-2}$ after $600 \mathrm{~s}$ (Fig. 4(A) and Table 1, Entry 4). ${ }^{50}$ Besides, the photocurrent and the open-circuit photovoltage of the photoanode are strongly dependent on the quantity of deposited $\mathrm{IrO}_{2}$ : they reach a maximum for $0.50 \mathrm{pmol} . \mathrm{cm}^{-2}$ of $\mathrm{IrO}_{2}$ and drop off for superior loadings. This none monotonic behavior was ascribed to a rapid charge recombination (also denoted electron scavenging $\left(\mathrm{k}_{\mathrm{scav}}\right)$, Fig. $\left.4(\mathrm{~B})\right)$ between the photo-injected electrons within the $\mathrm{TiO}_{2}$ conduction band and the $\mathrm{IrO}_{2}$ particle, the latter competing with the back electron transfer to the oxidized Ru3 ( $k_{\text {recomb}}$, Fig. $4(B))$. This assumption was confirmed by electrochemical impedance spectroscopy (EIS) since the lifetime of electrons photoinjected within the $\mathrm{TiO}_{2} \mathrm{CB}$ decreases from $6.25 \mathrm{~ms}$ without $\mathrm{IrO}_{2}$ to $4 \mathrm{~ms}$ in presence of $\mathrm{IrO}_{2}\left(1.79 \mathrm{pmol} . \mathrm{cm}^{-2}\right)$.

The group of Mallouk also showed that the nature and the acidity of solvent used for the dye grafting strongly influence the OER performances of the photoanode. ${ }^{49}$ When an acidic aqueous solvent is used for the dye deposition, weaker photocurrents and open-circuit photovoltages are obtained compared with organic solvents as DMSO or ethanol. Based on an EIS study, the authors proposed that the proton intercalation into $\mathrm{TiO}_{2}$ induces the formation of $\mathrm{Ti}^{\mathrm{ill}}$ sites which promotes the charge recombination with the photoinjected electrons and thus the loss of photocurrent. This hypothesis can also explain the rapid decay of the photocurrent during the light-driven water oxidation under acidic conditions that releases protons at the surface of the photoanode.

Finally, Mallouk and co-workers ${ }^{72}$ drew a complete kinetic picture of the electron transport operating within such hybrid photoanodes under an open-circuit regime by correlating EIS measurements with transient photocurrent and phototovoltage (Fig. 4(C)). Since the electron transport occurs in three dimensions, the authors calculated second-order rate constants with units of $\mathrm{cm}^{3} \mathrm{~s}^{-1}$, which are equivalent to the $\mathrm{M}^{-1} \mathrm{~s}^{-1}$ units employed for bimolecular electron transfers in solution. It is well known that the first event in these hybrid photoanodes, the electron injection from excited Ru3 dyes into $\mathrm{TiO}_{2}$, displays a high quantum yield and takes place at a time scale from femtoseconds to hundreds of picoseconds. $^{73,74}$
(A)
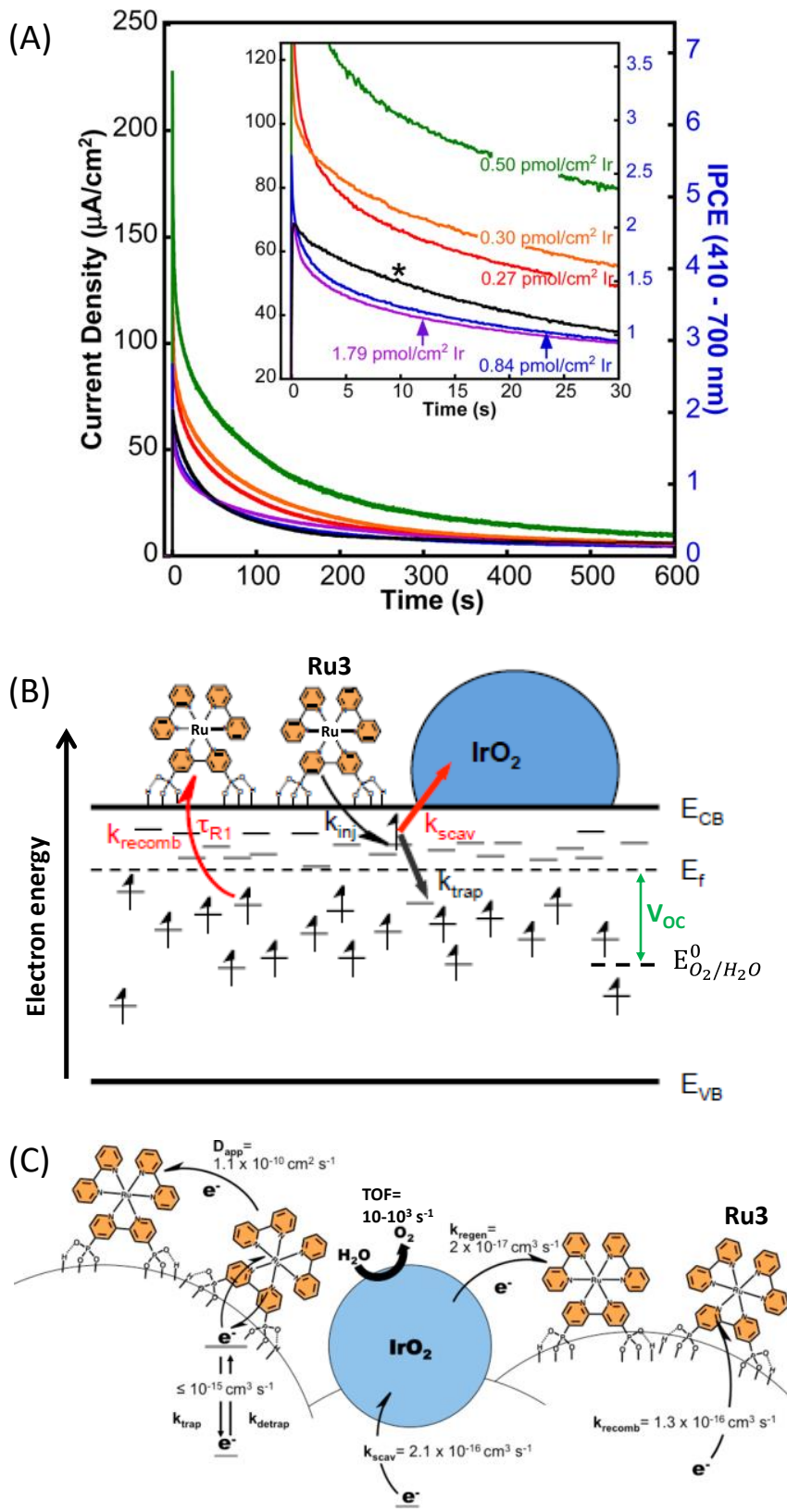

Fig. 4. (A) Transient photocurrent recorded at $0.1 \mathrm{~V} v \mathrm{Ag} / \mathrm{AgCl}$ in function of time in an aqueous buffered solution at $\mathrm{pH} 6.8$ with hybrid photoanodes $\mathrm{FTO} / \mathrm{TiO}_{2} / \mathbf{R u}$ /cat using sintered $\mathrm{IrO}_{2}$ (Ir loading between 0.27 and 1.79 pmol.cm $\left.{ }^{-2}\right)$ or citrate-capped $\mathrm{IrO}_{\mathrm{x}}\left(0.5 \mathrm{pmol} . \mathrm{cm}^{-2}\right.$, denoted by $\left.{ }^{*}\right)$ particles as catalyst, developed by Mallouk and coworkers (reproduced from ref ${ }^{50}$ with the permission from the American Chemical Society, Copyright 2014). (B) Energy diagram displaying the conduction $\left(E_{C B}\right)$ and valence $\left(E_{V B}\right)$ bands, the Fermi level $\left(E_{f}\right)$ of $\mathrm{TiO}_{2}$, along with the different electron transfer processes occurring within the hybrid photoanode of $\mathrm{FTO} / \mathrm{TiO}_{2} / \mathrm{Ru} 3 / \mathrm{IrO}_{2}$, such as the photo-injection of electron into the low-lying surface states $\left(\mathrm{k}_{\mathrm{inj}}\right)$, the trapping of the injected electrons into states below the Fermi level $\left(k_{\text {trap }}\right)$, the scavenging of these electrons by $\mathrm{IrO}_{2}\left(\mathrm{k}_{\text {scav }}\right)$, the charge recombination between the trap states and the oxidized Ru3 $\left(\mathrm{k}_{\text {recomb }}\right)$, the electron transfer from $\mathrm{IrO}_{2}$ to the oxidized Ru3 inducing its regeneration ( $\left.\mathrm{k}_{\text {regen }}\right)$, and the cross-surface electron diffusion (or the hole transport) between dyes with the $D_{\text {app }}$ coefficient. (C) Kinetics of electron transfers involved in the photocatalytic activity of the photoanode (reproduced from ref $^{72}$, with the permission from the American Chemical Society, Copyright 2015). 
Nevertheless, they showed via their model that only $2 \%$ of photo-injected electrons are trapped in the deep states below the Fermi level and contribute to the generation of the photocurrent. The other $98 \%$ remain in the shallow states just below the $\mathrm{CB}$ (i.e. above the Fermi level, see Fig. 4(B)) and recombine rapidly with the oxidized Ru3. The second-order rate constant of electron trapping $\left(k_{\text {trap }}\right)$ in deep states was approximated between $10^{-14}$ and $10^{-15} \mathrm{~cm}^{3}$ $\mathrm{s}^{-1}$, which is 80 times faster than the charge recombination between these deeply trapped electrons and the oxidized Ru3 $\left(\mathrm{k}_{\text {recomb }}=1.3 \mathrm{x}\right.$ $10^{-16} \mathrm{~cm}^{3} \mathrm{~s}^{-1}$ ), but also much slower than the charge recombination from the shallow states. Once oxidized, the Ru3 dye is able to oxidize the $\mathrm{IrO}_{2}$ catalyst with an estimated kinetics $\left(\mathrm{k}_{\text {regen }}\right)$ of $2 \times 10$ ${ }^{17} \mathrm{~cm}^{3} \mathrm{~s}^{-1}$, corresponding to a low bimolecular rate constant of $1.2 \mathrm{x}$ $10^{4} \mathrm{M}^{-1} \mathrm{~s}^{-1}$. The slow electron transfer from $\mathrm{IrO}_{2}$ to the oxidized Ru3 was explained by the fact that the dye is chemically grafted on the semiconducting electrode promoting the charge recombination with $\mathrm{TiO}_{2}$, while Ru3 is not in proximity to the catalyst particles. When oxidized, the $\mathrm{IrO}_{2}$ particles can in turn oxidize water to $\mathrm{O}_{2}$. However the catalysis can also be short-circuited by a fast scavenging of electrons lying in the shallow states by $\mathrm{IrO}_{2}$ with a rate constant of $\left(\mathrm{k}_{\text {scav }}\right) 2.1 \times 10^{-16} \mathrm{~cm}^{3} \mathrm{~s}^{-1}$. This study confirms that the slow electron transfer between the molecular photosensitizer and the metal oxide catalyst is the weak point of such hybrid photoanodes, and that the slow dye regeneration by $\mathrm{IrO}_{2}$ competes directly with very fast recombination and scavenging processes, limiting their photocatalytic performance. In other words, the quantum yield for water-splitting with hybrid $\mathrm{TiO}_{2} / \mathrm{Ru} / \mathrm{IrO}_{2}$ photoanodes is low since the charge recombination reaction at its surface is faster than the oxidation of the metal oxide catalyst or the catalytic four-electron oxidation of water.

The Murray's group ${ }^{52}$ has made a significant improvement to the hybrid photoanodes developed by Mallouk by using a FTO semiconducting electrode coated by a nanoparticles film of ITO on which a thin layer of $\mathrm{TiO}_{2}$ (3.7 or $6.6 \mathrm{~nm}$ ) was deposited by atomic layer deposition (ALD) (denoted nanolTO/TiO ${ }_{2} ; 3.2 \mu \mathrm{m}$ of thickness) (Fig. 5(A)). When a Ru tris-bipyridine phosphonate dye (Ru4) and $\mathrm{IrO}_{\mathrm{x}}$ nanoparticles are successively deposited on the core/shell $\mathrm{FTO} /$ nanolTO/ $/ \mathrm{TiO}_{2}$ electrode by soaking, a clear increase of the photocurrent efficiency is observed by a factor of 2.4 and 2.7 for a $\mathrm{TiO}_{2}$ layer of $3.7 \mathrm{~nm}$ and $6.6 \mathrm{~nm}$, respectively, in comparison to a photoanode with a regular mesoporous $\mathrm{TiO}_{2}$ film without nanolTO (i.e. $\mathrm{FTO} / \mathrm{TiO}_{2} / \mathrm{Ru} 4 / \mathrm{IrO}_{\mathrm{x}}$ ). The marked difference of photocurrent with and without nanolTO was ascribed to a slower back electron transfer between oxidized Ru4 and $\mathrm{TiO}_{2}$ within the core/shell photoanode, which could be due to a fast electron transport via the thin $\mathrm{TiO}_{2}$ layer to nanolTO and then to the counter electrode. In addition, the authors demonstrated that the photocurrent intensity of $\mathrm{FTO} /$ nanolTO/TiO $/ \mathrm{Ru} 4 / \mathrm{IrO}_{\mathrm{x}}$ depends on both the thickness of the $\mathrm{TiO}_{2}$ layer and the applied bias (Fig. $5(\mathrm{~B})$ ). With a bias of $0 \mathrm{~V}$ vs $\mathrm{Ag} / \mathrm{AgCl}$ at $\mathrm{pH} 5.8$, the core/shell photoanode displays a modest photocurrent of $c a .30$ and $50 \mu \mathrm{A} \mathrm{cm}{ }^{-2}$ respectively with a $\mathrm{TiO}_{2}$ layer of 3.7 and $6.6 \mathrm{~nm}$. Increasing the bias until $+0.5 \mathrm{~V}$ allows increasing the respective photocurrents until ca. 60 and $200 \mu \mathrm{A} \mathrm{cm}{ }^{-2}$ (Table 1, Entry 5); the latter being the highest photocurrent obtained with a hybrid photoanode using a ruthenium dye. It is noteworthy that the increase of photocurrent with the increase of bias cannot be attributed to a direct electro-oxidation of water on $\mathrm{IrO}_{\mathrm{x}}$, since the latter needs a potential of $+0.9 \mathrm{~V} v \mathrm{Ag} / \mathrm{AgCl}$ at $\mathrm{pH} 5.8$ to catalyze this reaction.

Nevertheless, during a long-term photolysis, the photocurrent decrease with $\mathrm{FTO} /$ nanolTO/TiO $/$ Ru4// $\mathrm{rO}_{\mathrm{x}}$ is rapid and significant because the Ru4 dye is released in solution owing to the hydrolysis of the phosphonate groups at near neutral pH (Fig. 5(C)). To avoid the detachment of the dye from the electrode surface, a very thin layer of $\mathrm{TiO}_{2}(1 \mathrm{~nm})$ was coated by ALD on FTO/nanolTO/TiO $/ 2 / \mathrm{Ru} 4$ before the deposition of $\operatorname{IrO}_{x}$ nanoparticles. The stabilized $\mathrm{FTO} /$ nanolTO/TiO $/ \mathrm{Ru} 4 / \mathrm{TiO}_{2} / \mathrm{IrO}_{\mathrm{x}}$ electrode sustains a photocurrent of $110 \mu \mathrm{A} \mathrm{cm}{ }^{-2}$ during a photolysis of $2 \mathrm{~h}$ with a $+0.3 \mathrm{~V} v \mathrm{sg} / \mathrm{AgCl}$ applied bias ( $\mathrm{pH}$ 5.8), displaying a remarkable longevity for a hybrid photoanode (Fig. 5(C) and Table 1, Entry 5).

(A)
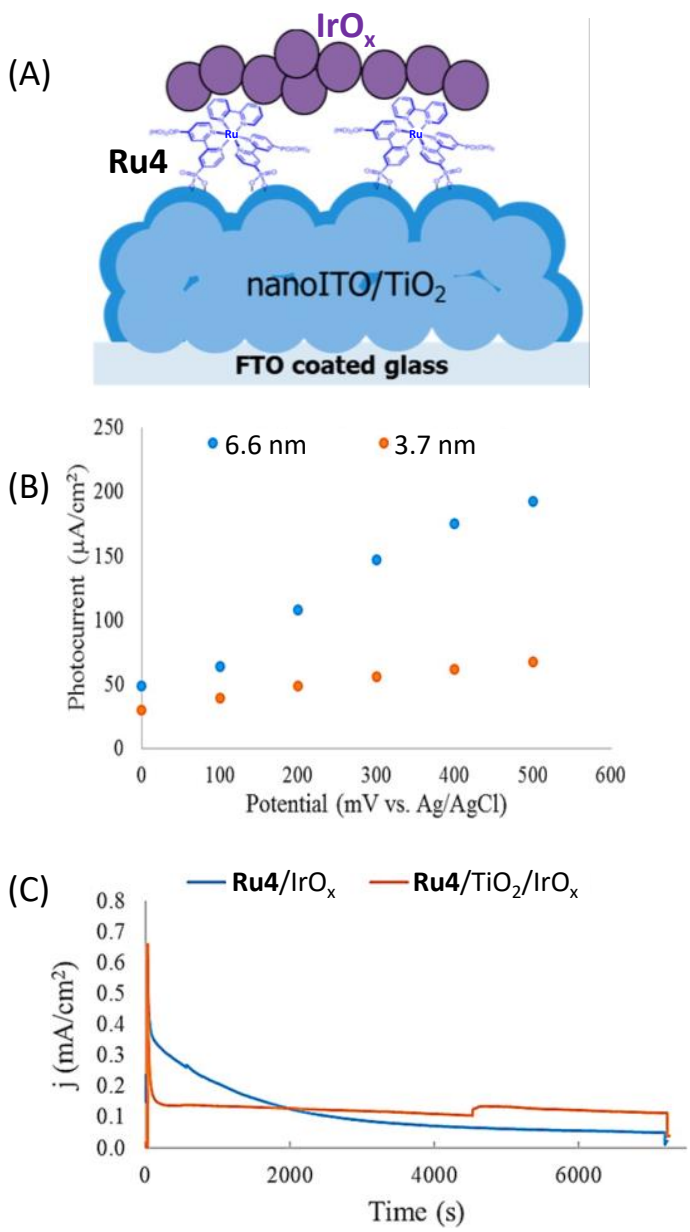

Fig. 5. (A) Schematic representation of the $\mathrm{FTO} /$ nanolTO/ $\mathrm{TiO}_{2} / \mathrm{Ru} 4 / \mathrm{IrO}_{x}$ photoanode developed by Murray and coworkers. ${ }^{52}$ (B) Photocurrent density in function of the anodic potential for $\mathrm{FTO} /$ nanolTO/TiO $/ 2 / \mathrm{Ru} / \mathrm{IrO}_{x}$ photoanodes with a $\mathrm{TiO}_{2}$ thickness of 3.7 (red) and $6.6 \mathrm{~nm}$ (blue) under illumination at $455 \mathrm{~nm}$, in an aqueous buffered solution at $\mathrm{pH}$ 5.8. (C) Chronoamperograms with $\mathrm{FTO} /$ nanolTO/ $\mathrm{TiO}_{2} / \mathrm{Ru}_{4}-\mathrm{IrO}_{x}$ (blue) and $\mathrm{FTO} /$ nanolTO/TiO $/ \mathrm{TR}_{2} / \mathrm{TiO}_{2} / \mathrm{IrO}_{\mathrm{x}}$ (red) with a $\mathrm{TiO}_{2}$ thickness of $6.6 \mathrm{~nm}$ under illumination at $455 \mathrm{~nm}$, in an aqueous buffered solution at $\mathrm{pH} 5.8$ and with a bias of $+0.3 \mathrm{~V} v s \mathrm{Ag} / \mathrm{AgCl}$ (reproduced from ref ${ }^{52}$, with the permission from the American Chemical Society, Copyright 2015). 
By contrast to these above reported examples of photoanodes involving iridium oxide, ${ }^{46-48,51,52} \mathrm{Na}$ and co-workers ${ }^{53}$ developed sensitized ruthenium $\mathrm{TiO}_{2}$ photoanodes with an earth abundant metal oxide as water oxidation catalyst, consisting of functionalized cobalt oxide nanoparticles $\left(\mathrm{CO}_{3} \mathrm{O}_{4}\right)$ (Fig. 6(A)). In this work, a new strategy to introduce nanoparticles water oxidation catalyst within water-splitting DS-PEC was investigated. Indeed, nanoparticles of $\mathrm{CO}_{3} \mathrm{O}_{4}$ were first synthetized and subsequently surface-modified by 3-aminopropyltriethoxysilane (APTES). Then, the functionalized $\mathrm{CO}_{3} \mathrm{O}_{4}$ were integrated to the ruthenium dye sensitized (Ru5) photoelectrode by a fast Schiff base reaction with the 4formylbenzoic acid which was co-adsorbed with Ru5 on $\mathrm{TiO}_{2}$; the Ru5 dye being primarily adsorbed onto mesoporous $\mathrm{TiO}_{2}$ via two phosphonate groups. Fig. $6(\mathrm{~B})$ displays the photocurrent density in function of time under visible light irradiation $(400 \mathrm{~nm})$ at $\mathrm{pH} 6.8$ in a phosphate buffer solution. The inset shows that the optimum bias applied is $+0.3 \mathrm{~V}$ vs $\mathrm{Ag} / \mathrm{AgCl}(\eta=-0.33 \mathrm{~V})$ producing a transient photocurrent density of $135 \mu \mathrm{A} \mathrm{cm}{ }^{-2}$. Irradiation of the $\mathrm{TiO}_{2} / \mathrm{Ru} 5$ electrode without cobalt catalyst produces a photocurrent density lower than $15 \mu \mathrm{A} \mathrm{cm}{ }^{-2}$ due to a fast charge recombination from $\mathrm{TiO}_{2}$ to Ru5 (Table 1, Entry 6), which is the direct consequence of the very slow water oxidation by the oxidized Ru5.
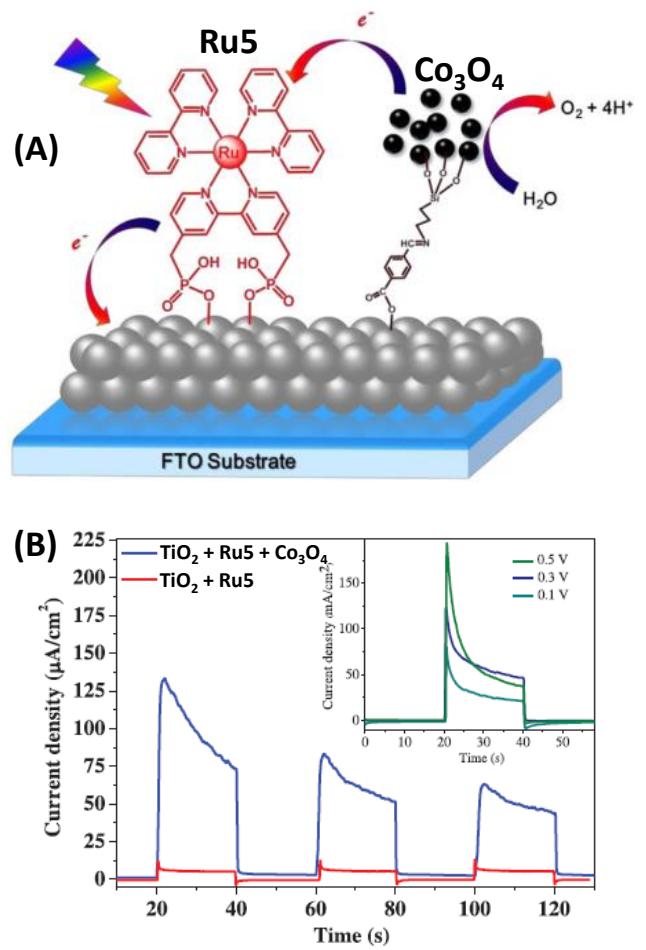

Fig. 6. (A) Schematic representation of the $\mathrm{FTO} / \mathrm{TiO}_{2} / \mathrm{Ru} 5 / \mathrm{CO}_{3} \mathrm{O}_{4}$ photoanode developed by $\mathrm{Na}$ and coworkers. ${ }^{53}$ (B) Corresponding transient photocurrent in a phosphate buffer solution at $\mathrm{pH} 6.8$ at different bias vs $\mathrm{Ag} / \mathrm{AgCl}$ in function of the time (reproduced from ref $^{53}$, with the permission from Elsevier, Copyright 2016).

Thus, the combination of Ru5 with the modified $\mathrm{Co}_{3} \mathrm{O}_{4}$ catalyst increases the photocurrent density of the photoanode by a factor of eight compared to that of a photoanode without $\mathrm{Co}_{3} \mathrm{O}_{4}$, due to a fast electron transfer from $\mathrm{CO}_{3} \mathrm{O}_{4}$ to the photoxidized Ru5 dye. However, with a decrease of the photocurrent density to $50 \mu \mathrm{A} \mathrm{cm}^{-2}$ (i.e. $40 \%$ of its initial value) after 3 cycles of 20 s ON-OFF illumination, the stability of this photoanode is not promising. ${ }^{53}$ This may be due to the low kinetics of water oxidation catalyzed by the modified $\mathrm{Co}_{3} \mathrm{O}_{4}$ particles, which therefore cannot give sufficient reducing equivalents to the oxidized dye, resulting in its decomposition or a fast charge recombination between $\mathrm{TiO}_{2}$ and Ru5.

In summary, ruthenium sensitized $\mathrm{TiO}_{2}$ photoanodes hybrid photoanodes display photocatalytic activities at negative overpotentials which is greatly desired, but the photocurrents are weak $\left(<100 \mu \mathrm{A} \mathrm{cm}{ }^{-2}\right.$ at a bias of $\left.0 \mathrm{~V} \mathrm{vs} \mathrm{Ag} / \mathrm{AgCl}(\eta=-0.69 \mathrm{~V})\right)$ and generally not stable. Only the Murray's photoanode $\mathrm{FTO} /$ nanolTO/ $/ \mathrm{TiO}_{2} / \mathrm{Ru} 4 / \mathrm{TiO}_{2} / \mathrm{IrO}_{\mathrm{x}}$ using thin layers of $n$-type semiconductor, one between the FTO electrode and $\mathrm{TiO}_{2}$ and the other one between the $\mathrm{Ru}$ dye and the $\mathrm{IrO}_{\mathrm{x}}$ catalyst, displays a photocurrent higher than $100 \mu \mathrm{A} \mathrm{cm}{ }^{-2}$ along with a remarkable stability ( $110 \mu \mathrm{A} \mathrm{cm}{ }^{-2}$ over $2 \mathrm{~h}$ of photolysis) but in that case the applied bias is also higher $(+0.3 \mathrm{~V}$ vs $\mathrm{Ag} / \mathrm{AgCl}(\eta=-0.39 \mathrm{~V}))$.

\section{Hybrid photoanodes with an organic chromophore}

\section{Polyheptazine chromophore}

In 2011, Beranek and coworkers ${ }^{54}$ studied the photo-oxidation of water to oxygen under visible light irradiation using a hybrid photoanode based on a novel class of inorganic/organic hybrid materials - nanocrystalline $\mathrm{TiO}_{2}$ modified at the surface by a thin layer $(<1-3 \mathrm{~nm})$ of polyheptazine $\left(\mathrm{TiO}_{2}-\mathrm{PH}\right)$ and loaded with $\mathrm{IrO}_{2}$ as oxygen-evolving co-catalyst (Fig. $7(\mathrm{~A})$ ). PH, also called graphitic carbon nitride $\left(g-C_{3} N_{4}\right)$, is a very attractive organic photosensitizer for light-driven water oxidation. Indeed, polyheptazine is extremely chemically stable, presents a strong absorption in the visible spectrum and its high conjugation promotes the electron transport through a graphite-like structure. In this work, the polyheptazine sheets were first generated on $\mathrm{ITO} / \mathrm{TiO}_{2}$ electrode by pyrolysis of urea at high temperature $\left(400^{\circ} \mathrm{C}\right)$. Then, $\mathrm{IrO}_{2}$ particles were deposited on $\mathrm{ITO} / \mathrm{TiO}_{2}-\mathrm{PH}$ electrode by soaking into a colloidal solution of iridium oxide, which was prepared by hydrolysis of an aqueous solution of $\mathrm{Na}_{2} \mathrm{ICl}_{6}$. In a phosphate buffer solution $(\mathrm{pH} 7)$ and with a bias of $+0.5 \mathrm{~V}$ vs $\mathrm{Ag} / \mathrm{AgCl}$, the $1 \mathrm{TO} / \mathrm{TiO}_{2}-\mathrm{PH} / \mathrm{IrO}_{2}$ photoanode displayed a light-driven evolution of $\mathrm{O}_{2}$ with a significant photocurrent of $c a .100 \mu \mathrm{A} \mathrm{cm}^{-2}$, along with a remarkable stability over $90 \mathrm{~min}$ of irradiation (Fig. 7(B) and Table 1, Entry 7). ${ }^{54,55}$ In this photoanode, after light absorption the $\mathbf{P H}$ film injects electrons into the $\mathrm{CB}$ of $\mathrm{TiO}_{2}$ and the holes generated in $\mathrm{PH}$ film are transferred to $\mathrm{IrO}_{2}$ to catalyze water oxidation. $\mathrm{TiO}_{2}$ photoelectrodes modified with $\mathrm{IrO}_{2}$ nanoparticles exhibit only negligible photocurrents and do not show any oxygen evolution (Fig. 7(B)). The authors have shown that a strong electronic coupling between $\mathrm{TiO}_{2}$ and $\mathrm{PH}$ allows a direct optical electron transfer from the $\mathrm{VB}$ of $\mathrm{PH}$ to the $\mathrm{CB}$ of $\mathrm{TiO}_{2}$ following light absorption (Fig. $7(\mathrm{C})$ ). 


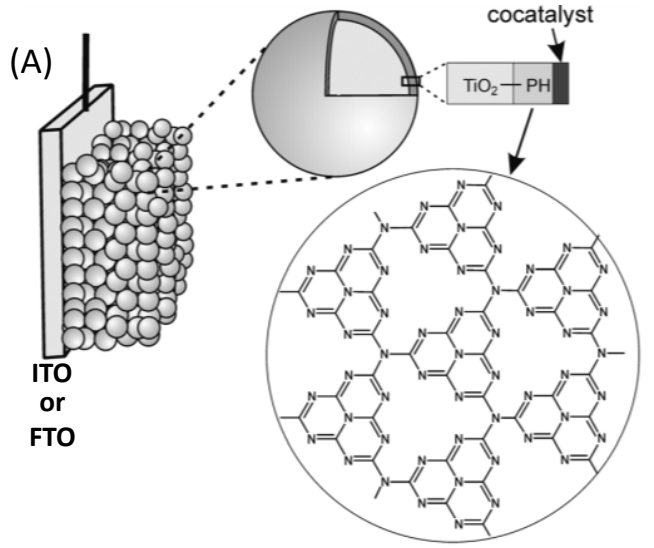

(B)

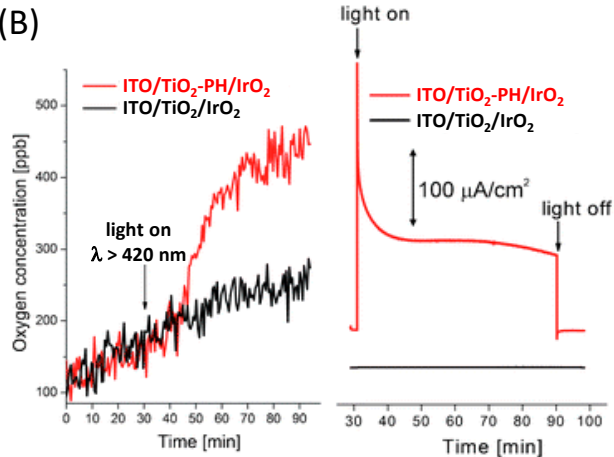

(C)

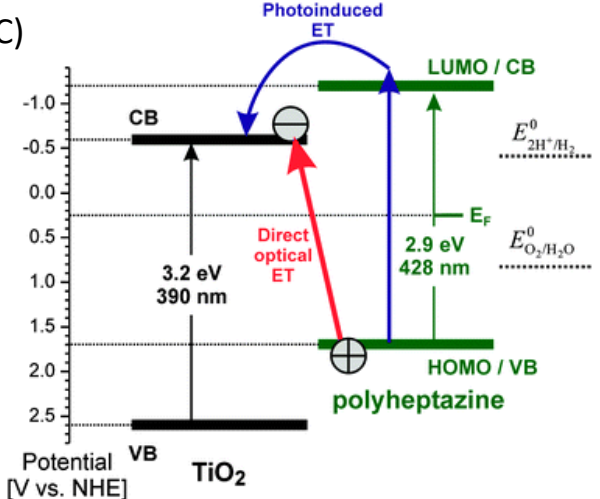

Fig. 7. (A) Schematic representation of the photoanodes developed by Beranek and coworkers ${ }^{54,57,60}$ consisting of ITO or $\mathrm{FTO} / \mathrm{TiO}_{2}$ loaded with a polyheptazine $(\mathrm{PH})$ film and a co-catalyst (e.g. $\left.\operatorname{IrO}_{2}, \mathrm{Co}-\mathrm{Pi}, \mathrm{CoO}(\mathrm{OH})_{x}\right)$ (reproduced from ref ${ }^{57}$, with the permission from Wiley, Copyright 2012). (B) Oxygen evolution (left) and corresponding transient photocurrent density (right) in function of time, measured with $1 \mathrm{TO} / \mathrm{TiO}_{2} / \mathrm{IrO}_{2}$ (black) and $\mathrm{ITO} / \mathrm{TiO}_{2}-\mathrm{PH} / \mathrm{IrO}_{2}$ (red) photoanodes under intermittent irradiation at $\lambda>$ $420 \mathrm{~nm}$, with a bias of $+0.5 \mathrm{Vvs} \mathrm{Ag} / \mathrm{AgCl}$ in a deaerated phosphate buffer at $\mathrm{pH}$ 7. (C) Potential diagram of the $\mathrm{TiO}_{2}-\mathrm{PH}$ interface $(\mathrm{pH} 7)$ showing the two photoexcitation pathways : the photo-induced electron transfer (blue) and the direct optical electron transfer (red) (reproduced from ref ${ }^{54}$, with the permission from The Royal Society of Chemistry, Copyright 2011).

Such process is correlated to an additional optical absorption band above $430 \mathrm{~nm}$ (until $~ 700 \mathrm{~nm}$ ), where polyheptazine and $\mathrm{TiO}_{2}$ do not absorb. Basically, the valence band of $\mathbf{P H}$, estimated at +1.7 $\checkmark$ vs NHE (i.e. $+1.5 \mathrm{~V}$ vs $\mathrm{Ag} / \mathrm{AgCl}, \mathrm{pH} 7$ ) by UV/Vis diffuse reflectance spectroscopy, is positive enough to induce water oxidation $(+0.82 \mathrm{~V}$ vs NHE, pH 7) from the $\mathrm{IrO}_{2}$ co-catalyst. The role of $\mathrm{IrO}_{2}$ is also to reduce the recombination of photogenerated charges at the interface of $\mathrm{TiO}_{2}-\mathrm{PH}$ at low bias potential. In other words, $\mathrm{IrO}_{2}$ particles reduce the holes accumulation within $\mathbf{P H}$, which is very important to reduce the need of external bias at hybrid photoanodes for the water splitting reaction. The photoconversion efficiency can be enhanced by increasing the amount of effective catalytic sites for water oxidation on the surface of the hybrid photoanode.

Beranek and coworkers ${ }^{56-58}$ subsequently investigated hybrid photoanodes of $\mathrm{TiO}_{2}$-Polyheptazine $\left(\mathrm{TiO}_{2}-\mathrm{PH}\right)$ with an earth abundant co-catalyst, a cobalt oxide deposited in phosphate buffer, denoted $\mathrm{Co}-\mathrm{Pi}$, which was initially reported by Nocera and coworkers. ${ }^{75-78}$ In this example, Co-Pi was photoelectrochemically deposited at $+0.4 \mathrm{~V}$ vs $\mathrm{Ag} / \mathrm{AgCl}$ in a phosphate buffer $(\mathrm{pH} 7)$ from $\mathrm{Co}^{2+}$ salt, in view to ensure its preferential generation at the sites with the highest concentration of photogenerated holes. The other advantage of such photoelectrochemical process is to fine tune the amount of Co-Pi deposited by monitoring the deposition progress over time with the photocurrent change. Fig. 8 displays the linear sweep voltammetry of $\mathrm{ITO} / \mathrm{TiO}_{2}-\mathrm{PH}$ with and without Co-Pi catalyst under on-off monochromatic irradiation at $450 \mathrm{~nm}$. The ITO/TiO ${ }_{2}^{-}$ $\mathrm{PH} / \mathrm{Co}-\mathrm{Pi}$ photoanode produces a photocurrent density of $\sim 100 \mu \mathrm{A}$ $\mathrm{cm}^{-2}$ at $0.5 \mathrm{~V}$ vs $\mathrm{Ag} / \mathrm{AgCl}$ (i.e. $1.12 \mathrm{~V}$ vs $\mathrm{RHE}(\eta=-0.43 \mathrm{~V})$ ), higher than that of a simple $\mathrm{ITO} / \mathrm{TiO}_{2}-\mathrm{PH}$. The photocurrent density of $\mathrm{ITO} / \mathrm{TiO}_{2}-\mathrm{PH} / \mathrm{Co}-\mathrm{Pi}$ increases to $190 \mu \mathrm{A} \mathrm{cm}{ }^{-2}$ by irradiating with a polychromatic visible light above $420 \mathrm{~nm}$ with a potential of $+0.5 \mathrm{~V}$ vs $\mathrm{Ag} / \mathrm{AgCl}$ at neutral $\mathrm{pH}$, but the latter decreases to $40 \mu \mathrm{A} \mathrm{cm}$ after $1 \mathrm{~h} 30$ of irradiation (Table 1, Entry 8). Under these experimental conditions, the $\mathrm{ITO} / \mathrm{TiO}_{2}-\mathrm{PH} / \mathrm{Co}-\mathrm{Pi}$ photoanode is able to produce $\mathrm{O}_{2}$ consistently during $1 \mathrm{~h} 40$, attesting to a relatively good stability of the photoelectrode. ${ }^{57}$ Besides, no oxygen evolution was detected with the $1 \mathrm{TO} / \mathrm{TiO}_{2}-\mathrm{PH}$ photoelectrodes without cocatalyst (Fig. 9(A)), as well as with $\mathrm{TiO}_{2}$ photoelectrodes loaded only with Co-Pi.

The performance (activity and stability) of this hybrid photoanode was further improved by substituting Co-Pi particles (size of $5 \mathrm{~nm}$ ) with smallest particles of $\mathrm{CoO}(\mathrm{OH})_{\times}(\sim 1-2 \mathrm{~nm}){ }^{60}$ In that case, the $\mathrm{CoO}(\mathrm{OH})_{x}$ co-catalyst was chemically deposited on the $\mathrm{FTO} / \mathrm{TiO}_{2}-\mathrm{PH}$ electrode by successive immersions into a solution of $\mathrm{Co}\left(\mathrm{NO}_{3}\right)_{2}$ and then into a solution of weakly basic aqueous ammonia. In a phosphate buffer $(\mathrm{pH} 7)$, the resulting $\mathrm{FTO} / \mathrm{TiO}_{2}-$ $\mathrm{PH} / \mathrm{CoO}(\mathrm{OH})_{x}$ photoanodes outperformed photoanodes loaded with Co- $\mathrm{Pi}$ in terms of faradaic yield of $\mathrm{O}_{2}$ evolution (34 vs $17 \%$ respectively) and stability under long term irradiation (Fig. 9). This improved photocatalytic performance was ascribed to a higher loading of $\mathrm{CoO}(\mathrm{OH})_{x}$ on $\mathrm{FTO} / \mathrm{TiO}_{2}-\mathrm{PH}$ compared to $\mathrm{Co}-\mathrm{Pi}$ and a greater electroactive surface area of the photoanodes due to the small particles of $\mathrm{CoO}(\mathrm{OH})_{x}$. The improved performance also stems from the higher transparency of the $\mathrm{CoO}(\mathrm{OH})_{x}$ film owing to its ultrasmall nanoparticles, which does not hinder the excitation of $\mathrm{TiO}_{2}-\mathrm{PH}$ and promotes the photocatalytic process. The stability of $\mathrm{FTO} / \mathrm{TiO}_{2}-\mathrm{PH} / \mathrm{CoO}(\mathrm{OH})_{x}$ photoanodes was further significantly enhanced by using a borate buffer $(\mathrm{pH}$ 7.7) instead of a phosphate 
buffer ( $\mathrm{pH}$ 7) (Fig. 9(B)). Indeed, the photocurrent remains higher than $110 \mu \mathrm{A} \mathrm{cm}$ over a period of 4 hours under visible light irradiation at $+0.5 \mathrm{~V} v \mathrm{Ag} / \mathrm{AgCl}$ (Table 1, Entry 9).

From a study by X-ray absorption spectroscopy (XAS), the authors related the higher stability in borate electrolyte to an increase in structural order of $\mathrm{CoO}(\mathrm{OH})_{x}$ after photoelectrocatalysis, which corresponds to the partial oxidation of the initially highly disordered $\mathrm{CoO}(\mathrm{OH})_{x}$ nanoparticles. Besides, DFT calculations suggest that this order is governed by the chemical interactions between the electrolyte anions and the cobalt ions at the highest oxidation states generated during photoelectrocatalysis. Thus, borate anions bind to cobalt cations much less covalently than phosphate anions and the ionic bonds between borate and $\mathrm{CoO}(\mathrm{OH})_{x}$ are more flexible due to a lower activation barrier for redirection, promoting a structural order within the nanoparticles. This study showed the strong influence of the structure and the optical properties of co-catalysts as well as of the nature of the electrolyte on the performance and stability of photoanodes devoted to water oxidation. To sum up, hybrid photoanodes using a polyheptazine film co-deposited on a $\mathrm{TiO}_{2}$ electrode with a metal oxide catalyst display significant photocurrents $\left(>100 \mu \mathrm{A} \mathrm{cm}{ }^{-2}\right)$ at a slightly negative overpotential ( $\eta \sim-0.1 \mathrm{~V}$, bias of $0.5 \mathrm{~V} \mathrm{vs} \mathrm{Ag} / \mathrm{AgCl}$ ) along with a good stability up to 4 hours with $\mathrm{CoO}(\mathrm{OH})_{x}$ nanoparticles in borate buffer. This promising performance could be related to the robustness of polyheptazine even at the oxidized state and the good mobility of hole within the polyheptazine film that competes with the charge recombination between $\mathrm{TiO}_{2}$ and $\mathrm{PH}$, and thus contributes to a sustained catalytic photocurrent.

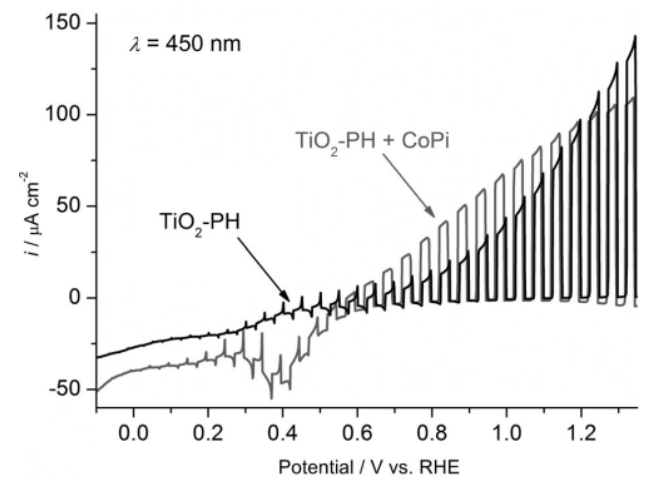

Fig. 8. Transient photocurrent density measured at $1 \mathrm{TO} / \mathrm{TiO}_{2}-\mathbf{P H}$ photoelectrodes with and without $\mathrm{Co}-\mathrm{Pi}$, under intermittent irradiation at $\lambda$ $=450 \mathrm{~nm}$ ( $5 \mathrm{~s}$ light, $5 \mathrm{~s}$ dark), at cathodic potential sweep of $5 \mathrm{mV} \mathrm{s}^{-1}$ in a deaerated phosphate buffer at $\mathrm{pH} 7$ (reproduced from ref $^{57}$, with the permission from Wiley, Copyright 2012).

\section{Perylene chromophore}

Some examples of hybrid photoanodes with perylene diimide (PDI) chromophores have been recently published. ${ }^{61-63}$ PDIs are interesting chromophores owing to their robustness with good thermal and photochemical stability, their strong absorption in the visible spectrum and their relatively low cost.
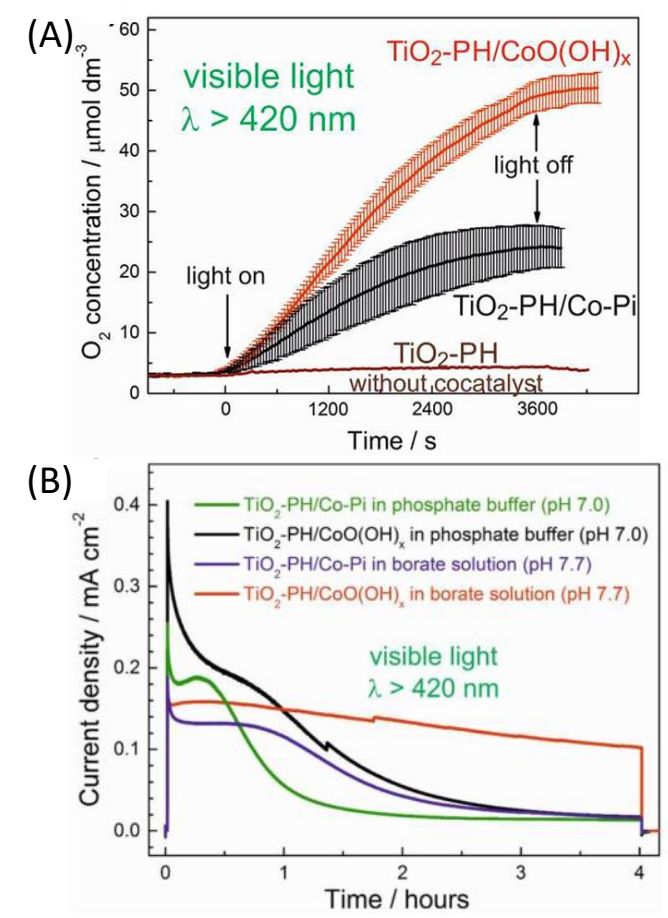

Fig. 9. (A) Photocatalytic oxygen evolution in function of time under visible light irradiation in a phosphate buffer $(\mathrm{pH} 7)$ at $+1.12 \mathrm{~V}$ vs $\mathrm{RHE}$ of $\mathrm{FTO} / \mathrm{TiO}_{2}$ $\mathrm{PH} / \mathrm{CoO}(\mathrm{OH})_{x}$ (red), $\mathrm{FTO} / \mathrm{TiO}_{2}-\mathrm{PH} / \mathrm{Co}-\mathrm{Pi}$ (black) and $\mathrm{FTO} / \mathrm{TiO}_{2}-\mathrm{PH}$ (brown) photoanodes developed by Beranek and coworkers. $^{60}$ (B) Chronoamperograms with $\mathrm{FTO} / \mathrm{TiO}_{2}-\mathrm{PH} / \mathrm{CoO}(\mathrm{OH})_{\mathrm{x}}$ (black and red) and $\mathrm{FTO} / \mathrm{TiO}_{2}-\mathrm{PH} / \mathrm{Co}-\mathrm{Pi}$ (green and purple) under visible light irradiation in phosphate $(\mathrm{pH} 7)$ and borate $(\mathrm{pH} 7.7)$ buffers at $+1.12 \mathrm{~V}$ vs RHE (reproduced from ref $^{60}$, with the permission from the American Chemical Society, Copyright 2017).

Many PDIs exhibit also a highest occupied molecular orbital (HOMO) with a potential enough positive to oxidize water or to activate a water oxidation catalyst, a metal oxide or a molecular complex. ${ }^{79}$ All of these features make PDIs interesting candidates as photosensitizer for water-splitting reactions. However, the implementation of PDI in dye-sensitized semiconducting electrodes remains limited due to a low oxidation potential at excited state preventing efficient charge injection into the $C B$ of many semiconductors. ${ }^{63}$ PDIs employed within photoanodes have thus to be carefully designed in view to adjust the energy levels of their molecular orbitals to those of the $\mathrm{CB}$ of SC and of the catalytic onset of water oxidation by the co-catalyst.

The first example of a hybrid photoanode for water oxidation based on perylene dye was published by Finke and co-workers ${ }^{61}$ in 2014 (Fig. 10(A)). To this aim, a novel PDI dye functionalized with two phosphonate groups on the imide positions $\left(\mathrm{N}, \mathrm{N}^{\prime}\right.$ bis(phosphonomethyl)-3,4,9,10-perylenediimide, denoted PMPDI) was synthetized. Thin films of PMPDI were deposited onto ITO electrodes by spin coating in basic aqueous solution and then the phosphonate groups were protonated by immersion in acidic solution to render the film insoluble in neutral or acidic medium. In view to promote water oxidation, $\mathrm{CoO}_{x}$ particles were then photoelectrochemically deposited by applying a potential of $+0.70 \mathrm{~V}$ 
vs $\mathrm{Ag} / \mathrm{AgCl}$ during $5 \mathrm{~min}$ to the ITO/PMPDI electrode immersed in a phosphate buffer $\left(\mathrm{pH}\right.$ 7) containing $1 \mathrm{mM}$ of $\mathrm{Co}\left(\mathrm{NO}_{3}\right)_{2}$ (illumination with a Xe lamp, $100 \mathrm{mWcm}^{-2}$ ). The photoelectrochemical process was chosen to preferentially deposit the catalyst in high concentration in areas where the holes are photogenerated, as previously described. ${ }^{57,80}$ With the ITO/PMPDI/CoO electrodes, visible-light assisted water oxidation was obtained with a photocurrent density of about $150 \mu \mathrm{A} \mathrm{cm}{ }^{-2}$ at an applied bias of $+1.0 \mathrm{~V}$ vs $\mathrm{Ag} / \mathrm{AgCl}(\eta=0.38 \mathrm{~V})$ in a phosphate buffer aqueous solution at $\mathrm{pH} 7$, with a stability over $300 \mathrm{~s}$ (Table 1, Entry 10). Fig. 10 (B) shows the linear sweep voltammetry of the ITO/PMPDI electrode with and without $\mathrm{CoO}_{x}$, and of the bare ITO, under on-off cycles of light irradiation. Almost no photocurrent was measured for bare ITO and relatively small photocurrents for ITO/PMPDI $(<10$ $\mu \mathrm{A} \mathrm{cm}^{-2}$ ) (Fig. 10(B)). The oxidation of water was confirmed by the direct detection of $\mathrm{O}_{2}$ obtained under an applied bias of $+0.90 \mathrm{~V} v \mathrm{vs}$ $\mathrm{Ag} / \mathrm{AgCl}$, which corresponds to a faradaic efficiency of $80 \pm 15 \%$. The quantum efficiency of this hybrid photoanode for water oxidation was $\sim 1 \%$. When analogous photoanodes were prepared with a perylene diimide derivative having two alkyl groups in place of the phosphonate groups of PMPDI, the photocurrent obtained was about one order of magnitude smaller than with the typical ITO/PMPDI/CoO ${ }_{x}$. This is due to the fact that, with this dye, only traces of cobalt were deposited as shown by XPS measurements. These results provide evidence that the phosphonate groups of the PMPDI strongly bond the $\mathrm{CoO}_{x}$ particles, and this could accelerate the electron transfers from the co-catalyst to the organic dye and minimize the charge recombination at the photoanode surface.

Although the ITO/PMPDI/ $\mathrm{COO}_{\mathrm{x}}$ anodes are capable of lightdriven water oxidation, their efficiency are limited by low light harvesting (only about $12 \%$ of incident light is adsorbed by the thin PMPDI films) and low charge transfer efficiency as well as an effective charge recombination. However, thicker films absorb more light but exhibit lower photocurrents, due to the low exciton diffusion lengths of this organic material. Despite these limitations, this study showed for the first time that water oxidation can be achieved photochemically by a thin film composed of a monolayer of molecular organic dye coupled to a water oxidation catalyst.

In view to improve the performance of their photoanode, Finke and co-workers ${ }^{62}$ introduced an inorganic semi-conductor, consisting of a nanostructured metal oxide of $\mathrm{TiO}_{2}, \mathrm{SnO}_{2}$ or $\mathrm{WO}_{3}$, to design a dye-sensitized photoelectrochemical cell (DS-PEC) (see Fig. 1). These semiconductors, deposited onto FTO electrodes, were photosensitized by the PMPDI dye (Fig. 11(A)). The dye-sensitized mesoporous semiconducting electrode (i.e. FTO/SC/PMPDI) would absorb more light due to its higher surface area compared to the simple deposition of PMPDI dye on flat ITO (ITO/PMPDI), by keeping the thickness of the dye monolayer. To increase the stability, PMPDI was chemisorbed via one of the phosphonate groups onto the SC surfaces, and not spin-coated as in their previous work. ${ }^{61}$
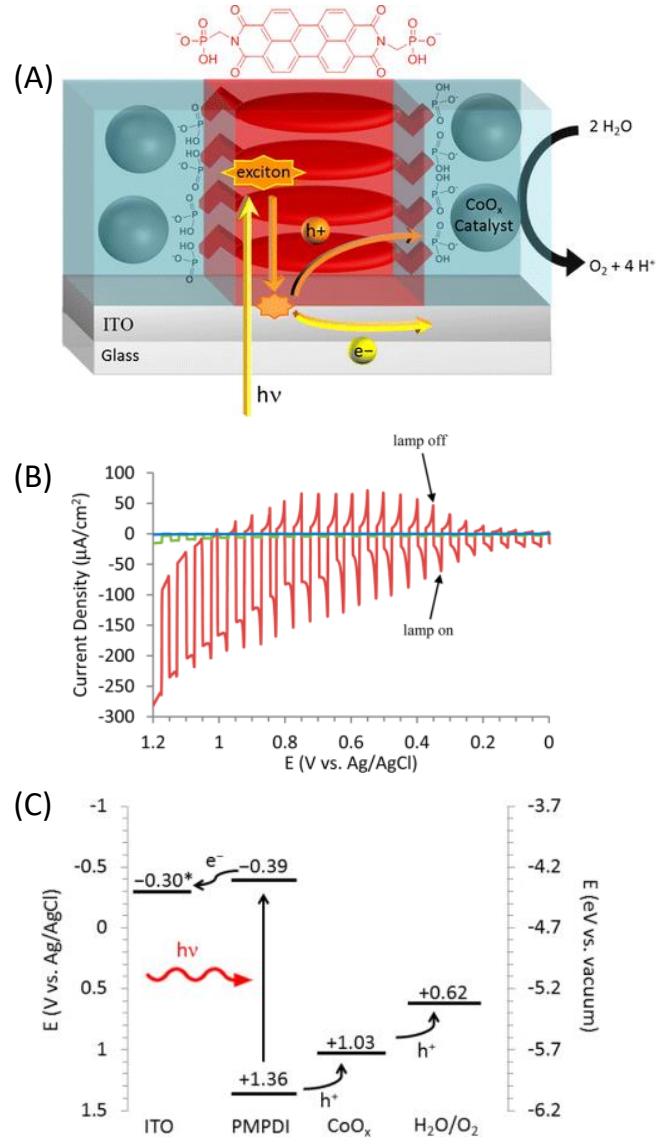

Fig. 10. (A) Schematic representation of the ITO/PMPDI/CoO photoanode developed by Finke and coworkers. $^{61}$ (B) Corresponding transient photocurrent density in function of the applied potential measured with

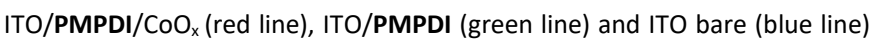
under intermittent irradiation ( $5 \mathrm{~s}$ light, $5 \mathrm{~s}$ dark), using a potential sweep of $5 \mathrm{mV} \mathrm{s}^{-1}$ in a deaerated phosphate buffer at $\mathrm{pH}$ 7. (C) Band diagram for the ITO/PMPDI/CoO ${ }_{x}$ photoanode with the estimated energy levels (given vs $\mathrm{Ag} / \mathrm{AgCl})$, the actual potential * of ITO $(-0.3 \mathrm{~V})$ corresponds to the bias applied in this study (reproduced from ref ${ }^{61}$, with the permission from the American Chemical Society, Copyright 2014).

The driving force for the electron injection from the photoexcited dye (PMPDI*) into the conduction band of the different SCs increases in the order $\mathrm{TiO}_{2}<\mathrm{SnO}_{2}<\mathrm{WO}_{3}$ (Fig. 11(B); the $\mathrm{CB}$ energies being estimated by electrochemical photocurrent method). Consequently, it is expected that the photocurrent of the corresponding photoanodes using these SCs will follow the same trend. However, the chemisorption of PMPDI dye was less efficient on $\mathrm{SnO}_{2}$ than onto $\mathrm{TiO}_{2}$ and not at all effective onto $\mathrm{WO}_{3}$, due to the increasing acidity of the SC surface in the order $\mathrm{TiO}_{2}<\mathrm{SnO}_{2}<$ $\mathrm{WO}_{3}$, which disfavors the coordination of the phosphonate group on the metal. 
(A)

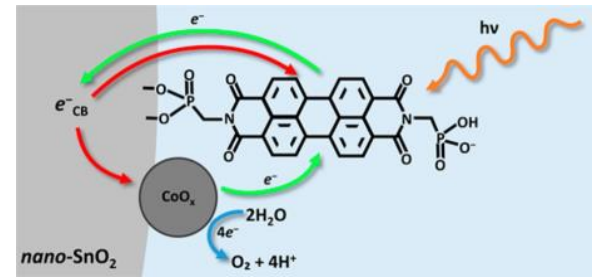

(B)
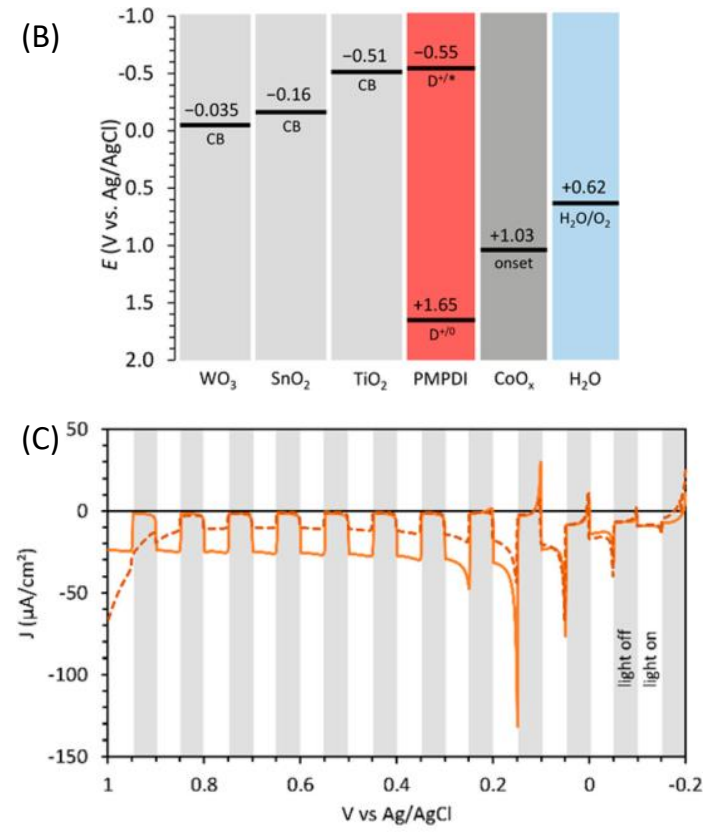

Fig. 11. (A) Schematic representation of the $\mathrm{FTO} / \mathrm{SnO}_{2} / \mathrm{PMPDI} / \mathrm{CoO}_{x}$ photoanode developed by Finke and coworkers ${ }^{62}$ (red arrows correspond to the charge recombination). (B) Estimated energy diagram for the $\mathrm{SC} / \mathrm{PMPDI} / \mathrm{CoO}_{x}$ system at pH 7, where SC was either $\mathrm{WO}_{3}$, or $\mathrm{SnO}_{2}$ or $\mathrm{TiO}_{2}$. (C) Corresponding transient photocurrent density in function of the applied potential for $\mathrm{FTO} / \mathrm{SnO}_{2} / \mathrm{PMPDI}$ before (solid line) and after (dashed line) photoelectrochemical deposition of $\mathrm{CoO}_{x}$ under intermittent irradiation $(5 \mathrm{~s}$ white light transients), using a potential sweep of $10 \mathrm{mV} \mathrm{s}^{-1}$ in a deaerated phosphate buffer at $\mathrm{pH} 7$ (reproduced from $\mathrm{ref}^{62}$, with the permission from the American Chemical Society, Copyright 2017).

Then, the relative efficiency of the electron transfer occurring on the surface of the $\mathrm{FTO} / \mathrm{TiO}_{2} / \mathrm{PMPDI}$ and $\mathrm{FTO} / \mathrm{SnO}_{2} / \mathrm{PMPDI}$ photoelectrodes before the deposition of the $\mathrm{CoO}_{x}$ particles was estimated by the measure of the photocurrent in presence of a sacrificial reductant as hydroquinone (denoted $\mathrm{H}_{2} \mathrm{Q}$ ) at $20 \mathrm{mM}$ in aqueous phosphate buffer at $\mathrm{pH} 7$. With a bias at $+0.2 \mathrm{~V} v \mathrm{Ag} / \mathrm{AgCl}$, the photocurrent produced by $\mathrm{FTO} / \mathrm{TiO}_{2} / \mathrm{PMPDI}$ with $\mathrm{H}_{2} \mathrm{Q}$ was much lower than that measured with $\mathrm{FTO} / \mathrm{SnO}_{2} / \mathrm{PMPDI}$, this latter reaching $1100 \mu \mathrm{A} \mathrm{cm}^{-2}$ with a light-harvesting efficiency of $99 \%$ at $490 \mathrm{~nm}$, the $\lambda_{\max }$ of the dye.

Due to the higher photocurrent obtained with the $\mathrm{SnO}_{2}$ substrate indicating a more efficient electron injection from the excited PMPDI dye into the SC, the $\mathrm{CoO}_{x}$ water oxidation catalyst was then photoelectrochemically deposited on $\mathrm{FTO} / \mathrm{SnO}_{2} / \mathrm{PMPDI}$ (Fig. 11(A)), following a similar procedure used in their previous work $^{61}$ (see above) except that a lower potential is applied in presence of $\mathrm{SnO}_{2}$ (i.e. $+0.2 \mathrm{~V}$ vs $\mathrm{Ag} / \mathrm{AgCl}$ ). This potential is not enough positive to directly oxidize $\mathrm{Co}(\mathrm{II})$ but sufficiently positive compared to the $\mathrm{CB}$ energy level of $\mathrm{SnO}_{2}$ to collect photoinjected electrons. Unfortunately, the transient photocurrent density measured with the $\mathrm{FTO} / \mathrm{SnO}_{2} / \mathrm{PMPDI} / \mathrm{CoO}_{x}$ photoanode $(\sim 10 \mu \mathrm{A}$ $\mathrm{cm}^{-2}$ between +0.2 and $+0.9 \mathrm{~V}$ vs $\mathrm{Ag} / \mathrm{AgCl}$ (i.e. $\eta=-0.42$ to $\left.+0.28 \mathrm{~V}\right)$ ) at $\mathrm{pH} 7$ decreases by a factor of 2-3 compared to that obtained without $\mathrm{CoO}_{\mathrm{x}}$ deposition ( $40 \mu \mathrm{A} \mathrm{cm}{ }^{-2}$ that decreases to $20 \mu \mathrm{A} \mathrm{cm}^{-2}$ over $5 \mathrm{~min}$ ) (Fig. 11(C) and Table 1, Entry 11). The faradaic yield of $\mathrm{FTO} / \mathrm{SnO}_{2} / \mathrm{PMPDI} / \mathrm{CoO}_{x}$ was estimated to be $31 \%$ from quantification of $\mathrm{O}_{2}$ evolution using a generator-collector method. $^{50,81}$ This yield is lower than that of previous ITO/PMPDI/CoO photoanode ${ }^{61}$ (80 \%) due to an enhanced charge recombination between the photoinjected electrons in $\mathrm{SnO}_{2}$ and holes within $\mathrm{CoO}_{x}$ (also called "scavenging" process by Mallouk, see ref $^{51}$ ), which is most likely directly deposited on the $\mathrm{SnO}_{2}$ surface in the case of $\mathrm{FTO} / \mathrm{SnO}_{2} / \mathrm{PMPDI} / \mathrm{CoO}_{\mathrm{x}}$.

This $\mathrm{SnO}_{2} / \mathrm{PMPDI} / \mathrm{CoO}_{\mathrm{x}}$ system was the second example in the literature of a DS-PEC composed only by earth-abundant materials to successfully oxidize water (the first example was the $\mathrm{TiO}_{2}-\mathrm{PH} / \mathrm{Co}-$ Pi published in 2012 by Beranek, ${ }^{57}$ see above). From these results, the authors underline the importance of maintaining the water oxidation catalyst far away from the SC surface and not directly adsorbed on it, to prevent charge recombination reactions.

In 2015, Bignozzi and coworkers ${ }^{63}$ reported a water-oxidation DS-PEC consisting of a nanocrystalline $\mathrm{WO}_{3}$ film photosensitized with a cationic PDI- $\mathbf{N}^{+}$dye ((N,N'-Bis(2-(trimethylammonium)ethylene) perylene 3,4,9,10-tetracarboxylic acid bisimide) $\left.\left(\mathrm{PF}_{6}\right)_{2}\right)$ with co-deposited $\mathrm{IrO}_{2}$ as water oxidation catalyst (Fig. 12(A)). This dye is oxidized at a potential of $+1.7 \mathrm{~V}$ vs SCE in acetonitrile with a spectroscopic band gap of $2.36 \mathrm{eV}$ resulting in an oxidation potential of $-0.66 \mathrm{~V}$ vs SCE at the excited state. The redox properties of PDI- $\mathbf{N}^{+}$at the ground and excited states allowed an efficient lightdriven electron injection into $\mathrm{WO}_{3}$ and an effective hole transfer to $\mathrm{IrO}_{2}$. A spontaneous adsorption of this dye on the surface of the SC via aggregation and hydrophobic forces was observed. The $\mathrm{IrO}_{2}$ nanoparticles were co-deposited by different methods (Fig. 12(B)), namely drop casting (b), spin coating (c), spin coating and drying in warm air (d) and soaking (e). Under irradiation by visible light at $\lambda>$ $435 \mathrm{~nm}$, all $\mathrm{FTO} / \mathrm{WO}_{3} / \mathrm{PDI}-\mathrm{N}^{+}-\mathrm{IrO}_{2}$ photoelectrodes exhibit a photocurrent at a bias of $+0.5 \mathrm{~V}$ vs SCE in aqueous solution at $\mathrm{pH} 3$, which increases in the order, $\mathrm{a}<\mathrm{b}<\mathrm{c}<\mathrm{d}<\mathrm{e}$ (type $\mathrm{a}$, photoelectrode without $\left(\mathrm{IO}_{2}\right)$, consistent with electron transfers to the photogenerated oxidized state of the PDI-N ${ }^{+}$dye from $\mathrm{IrO}_{2}$, which in turn catalyzes water oxidation (Fig. 12(B)). The photocurrent can reach $\sim 70 \mu \mathrm{A} \mathrm{cm}{ }^{-2}$ (Table 1, Entry 12), at a potential close to $+0.5 \mathrm{~V}$ vs SCE (i.e. $+0.55 \mathrm{~V}$ vs $\mathrm{Ag} / \mathrm{AgCl}, \eta=-0.3 \mathrm{~V}$ at $\mathrm{pH} 3$ ), for the best photoelectrodes (types $c, d$ and e). This corresponds to an enhancement of about 4-fold compared to the photoelectrode without $\mathrm{IrO}_{2}$ (type a). The enhancement in photoanodic current is due to an efficient holes transfer from oxidized dye to $\mathrm{IrO}_{2}$. Besides, the transient photocurrents rapidly decrease due to the charge recombination process between $\mathrm{WO}_{3}$ and the oxidized PDI-N $\mathbf{N}^{+}$, that competes with hole transfer from oxidized PDI-N ${ }^{+}$to $\mathrm{IrO}_{2}$. 
(A)
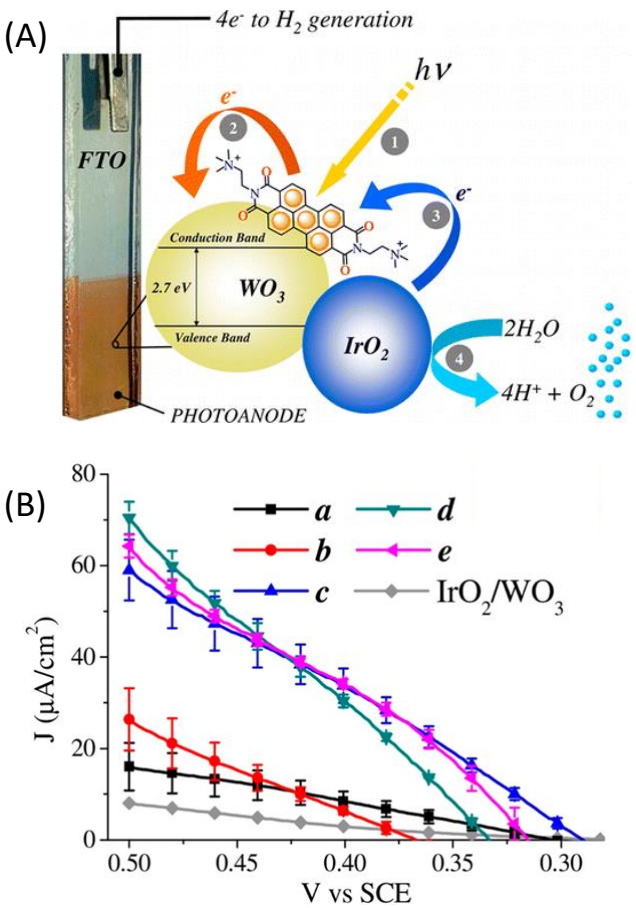

Fig. 12. (A) Schematic representation $\mathrm{FTO} / \mathrm{WO}_{3} / \mathrm{PDI}-\mathrm{N}^{+}-\mathrm{IrO} \mathrm{O}_{2}$ photoanode developed by Bignozzi and coworkers. ${ }^{63}$ (B) Corresponding photocurrent in function of the applied potential for photoelectrodes a-e, with visible light irradiation and a $435 \mathrm{~nm}$ cut off in aqueous $0.1 \mathrm{M} \mathrm{NaClO}_{4}$ solution at $\mathrm{pH} 3$. Photoelectrodes with different deposition methods of $\mathrm{IrO}_{2}$ nanoparticles on $\mathrm{FTO} / \mathrm{WO}_{3} / \mathrm{PDI}^{+} \mathrm{N}^{+}$: a-without $\mathrm{IrO}_{2} \mathrm{NPs}$, b-drop casting, c-spin coating, d-spin coating and drying with warm air, and e-soaking (reproduced from ref ${ }^{63}$, with the permission from the American Chemical Society, Copyright 2015).

The investigation of the charge transfer kinetics at $430 \mathrm{~nm}$ with the $\mathrm{FTO} / \mathrm{WO}_{3} / \mathrm{PDI}-\mathrm{N}^{+}$photoelectrode (without $\mathrm{IrO}_{2}$ ) revealed that light-driven electron injection into the conduction of $\mathrm{WO}_{3}$ from the excited PDI-N $\mathbf{N}^{+}$occurs in a few nanoseconds (rate constant of $0.4 \mathrm{x}$ $10^{9} \mathrm{~s}^{-1}$ ) and is $10^{3}$ times faster than the charge recombination which takes place at the microsecond scale. When $\mathrm{IrO}_{2}$ is deposited on FTO/ $\mathrm{WO}_{3} / \mathrm{PDI}^{+} \mathbf{N}^{+}$, the lifetime of the photooxidized PDI-N ${ }^{+}$is just divided by two, until $0.5 \mu \mathrm{s}$, since the hole transfer kinetics to $\mathrm{IrO}_{2}$ occurs at the same time scale than that of the charge recombination process between $\mathrm{WO}_{3}$ and the oxidized dye. Once again, the kinetic study of the electron transfers involved in hybrid photoanodes (i.e. Sc/molecular dyes/metallic catalyst) highlights the importance to minimize the charge recombination processes in view to promote the activation of the catalyst and to ensure high photocatalytic performance.

In summary, hybrid photoanodes with perylene dyes need significant overpotential ( $\eta \geq+0.28 \mathrm{~V}$, bias $\geq 0.9 \mathrm{~V} v \mathrm{Ag} / \mathrm{AgCl}$ ) or to be associated with a low band gap semiconductor $\left(\right.$ as $\mathrm{WO}_{3}$ ) for obtaining photocurrents around $70 \mu \mathrm{A} \mathrm{cm}^{-2}$.

\section{$\pi$-Conjugated naphthalene polymer based chromophore}

In 2015, Sivula and coworkers ${ }^{64}$ investigated a $n$-type $\pi$ conjugated naphthalene benzimidazole polymer as organic dye,

also called the poly[benzimidazobenzophenanthroline] (denoted BBL), to be used in a direct semi-conductor-liquid junction configuration for solar water oxidation (Fig. 13(A)). BBL is known for its exceptional stability and good electron mobility. BBL films were prepared on FTO electrodes by a spray deposition method from an aqueous BBL nanofibers dispersion. Under intermittent simulated solar illumination in buffered aqueous solution at $\mathrm{pH} 7$, a photocurrent density up to $230 \mu \mathrm{A} \mathrm{cm}{ }^{-2}$ at $1.23 \mathrm{~V}$ vs RHE was obtained in the presence of a hole scavenger $\left(\mathrm{SO}_{3}{ }^{2-}\right)$, with an optimized nanostructured film thickness of $120 \mathrm{~nm}$. The $\mathrm{SO}_{3}{ }^{2-}$ oxidation allows the investigation of the PEC properties of the BBL dye with minimum kinetic limitations. The FTO/BBL film was also investigated without $\mathrm{SO}_{3}{ }^{2-}$ in aqueous solution at different $\mathrm{pH}$ from 3.5 to 10.5. It was found that the photocurrent density increases with increasing $\mathrm{pH}$ (from $\sim 10$ to $30 \mu \mathrm{A} \mathrm{cm} \mathrm{cm}^{-2}$ at $+1.23 \mathrm{~V} v \mathrm{~s} \mathrm{RHE}$ ), but no $\mathrm{O}_{2}$ evolution was detected and no evidence of semi-conductor oxidation after 30 min was observed. Instead, the photooxidation reaction was found to be a two-electrons oxidation of water by the bare film into $\mathrm{H}_{2} \mathrm{O}_{2}$ which in turn is reduced at the anode to produce the hydroxyl radical $(\bullet \mathrm{OH})$. This later was quantified by a fluorescence test in presence of coumarin in solution.

In view to drive the four electron oxidation of water, an OER catalyst consisting of $\mathrm{Ni}-\mathrm{Co}$ nanoparticles, has been directly attached to the BBL surface by a solvothermal method from an aqueous solution of $\mathrm{NiSO}_{4} \cdot 6 \mathrm{H}_{2} \mathrm{O}$ and $\mathrm{Co}\left(\mathrm{NO}_{3}\right)_{2} \cdot 6 \mathrm{H}_{2} \mathrm{O}$. However no $\mathrm{O}_{2}$ was produced due to the poor catalyst attachment.

(A)

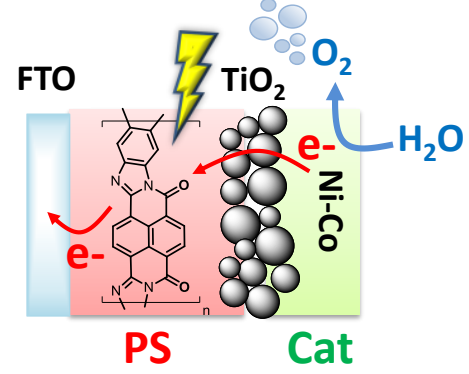

(B)

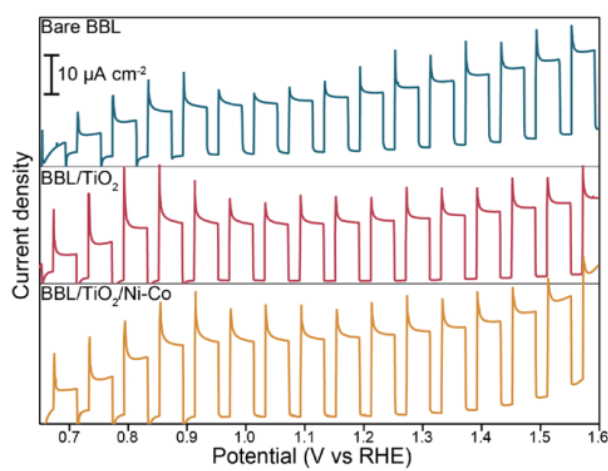

Fig. 13. (A) Schematic representation of the $\mathrm{FTO} / \mathrm{BBL} / \mathrm{TiO}_{2} / \mathrm{Ni}-\mathrm{Co}(\mathrm{BBL}=$ poly(benzimidazobenzophenanthroline)) photoanode developed by Sivula and coworkers. ${ }^{64}$ (B) Corresponding transient photocurrent density in function of the applied potential for spray deposited film of BBL $(230 \mathrm{~nm}$ thickness), before and after $\mathrm{TiO}_{2}$ deposition, and after co-deposition of $\mathrm{Ni}$-Co catalyst in aqueous phosphate buffer at $\mathrm{pH} 7$ (reproduced from ref ${ }^{64}$, with the permission from the American Chemical Society, Copyright 2015). 
The successful attachment of the catalyst was obtained when the $\mathrm{BBL}$ film is pretreated with a thin layer of $\mathrm{TiO}_{2}(\sim 1 \mathrm{~nm})$ deposited by ALD and acting as tunnel junction. Even if the application of $\mathrm{TiO}_{2}$ did not result in a significant change of the observed photocurrent density (from $\sim 15-20 \mu \mathrm{A} \mathrm{cm}{ }^{-2}$ ), a slight increase (up to $\sim 30 \mu \mathrm{A} \mathrm{cm}{ }^{-2}$ ) was observed upon application of the catalyst layer (Fig. 13(B) and Table 1, Entry 13). Molecular $\mathrm{O}_{2}$ was confirmed by gas chromatography during constant illumination chronoamperometry measurements $\left(\mathrm{j} \sim 10 \mu \mathrm{A} \mathrm{cm}{ }^{-2}\right)$ with a faradaic yield of $82 \pm 16 \%$.

In the same vein of Finke ${ }^{61,62}$ and Beranek's $s^{54,57,60}$ works, this study showed that robust $\pi$-conjugated organic semi-conductors are suitable for direct PEC water oxidation opening new perspectives for the design and optimization of photoanodes for solar water splitting.

\section{Free-base Porphyrin chromophore}

In 2015, Mallouk and co-workers ${ }^{51}$ reported the first examples of functional photoanodes devoted to water oxidation using freebase porphyrins as organic photosensitizer (Fig. 14). Crystalline $\mathrm{IrO}_{2}$ particles used as catalyst, were first deposited on the semiconducting $\mathrm{FTO} / \mathrm{TiO}_{2}$ electrode by a solvothermal method from a solution of citrate-capped $\mathrm{IrO}_{x}$, followed by a treatment at $450^{\circ} \mathrm{C}$, as previously described. ${ }^{50}$ Then, the porphyrins were chemisorbed via a carboxylate substituent on the resulting $\mathrm{FTO} / \mathrm{TiO}_{2} / \mathrm{IrO}_{2}$ electrodes by soaking.

A series of metal-free porphyrins with different substituents were synthesized in view to tune their redox and photophysical properties (Fig. 14(B)). They exhibit Soret bands at $\sim 410 \mathrm{~nm}$ with high extinction coefficients $\left(\varepsilon>10^{5} \mathrm{M}^{-1} \mathrm{~cm}^{-1}\right)$, along with intense $Q$ bands between 500 and $650 \mathrm{~nm}\left(1600<\varepsilon<22500 \mathrm{M}^{-1} \mathrm{~cm}^{-1}\right)$, offering the possibility to activate the photoanodes sensitized by these porphyrins at two different wavelengths in the visible spectrum (410 and $590 \mathrm{~nm}$ ). When chemisorbed on $\mathrm{TiO}_{2}$, the oxidation of these porphyrins is electrochemically irreversible in aqueous solution with an anodic peak $\left(E \mathrm{p}_{\mathrm{a}}\right)$ located between +1.02 and $+1.29 \mathrm{~V} v \mathrm{Ag} / \mathrm{AgCl}$, although some of them present a reversible systems in non-aqueous electrolyte. These potentials are positive enough to activate of the $\mathrm{IrO}_{2}$ catalyst for water oxidation. Besides, considering the energy level of their singlet excited state $\left(1.87<E_{00}\right.$ $<1.96 \mathrm{eV}$ ), the oxidation potential of the porphyrins at the excited state become sufficiently negative for most of these photosensitizers $\left(-0.94<E_{\text {ox }}{ }^{*}<-0.62 \mathrm{~V}\right.$ vs $\left.\mathrm{Ag} / \mathrm{AgCl}\right)$ to inject an electron into the conduction band of $\mathrm{TiO}_{2}$, which is estimated at $-0.81 \mathrm{~V} v s \mathrm{Ag} / \mathrm{AgCl}$ at $\mathrm{pH} 6.8$.

Despite the variability of the spectral and electrochemical properties of these organic dyes, the majority of the $\mathrm{FTO} / \mathrm{TiO}_{2} /$ porphyrin//rO $\mathrm{I}_{2}$ photoanodes exhibit a non-negligible photocurrent with quite similar intensity under full visible light illumination (> $410 \mathrm{~nm}$ ) or red light illumination (> $590 \mathrm{~nm}$ ). Direct observance of $\mathrm{O}_{2}$ with a faradaic yield close to $100 \%$ demonstrates that the photocurrent is related to water oxidation. For instance, the photoanode sensitized by DMEP displayed an anodic photocurrent spike of $80 \mu \mathrm{A} \mathrm{cm}{ }^{-2}$ with a bias of $0.1 \mathrm{~V} v s \mathrm{Ag} / \mathrm{AgCl}$ (Fig. 14(C)). However, the photocurrent rapidly decreases achieving $\sim 10 \mu \mathrm{A} \mathrm{cm}{ }^{-2}$ after $10 \mathrm{~min}$ of visible irradiation (Table 1, Entry 14). The poor stability of the photocurrent is not due to the dye degradation, since the UV-visible spectra of the electrodes before and after photoelectrolysis generally show no change, confirming the stability of free-base porphyrin dyes. Otherwise, these photoelectrodes sensitized by free-base porphyrins generated roughly half of the photocurrent of analogous photoanodes sensitized by $\left[\mathrm{Ru}(\mathrm{bpy})_{2}\left(4,4^{\prime}-\left(\mathrm{PO}_{3} \mathrm{H}_{2}\right)(\mathrm{bpy})\right)\right]$ (Ru2) under visible irradiation $(>410 \mathrm{~nm})$, although the latter are not active under red light illumination (> $590 \mathrm{~nm}$ ). The authors attributed the poor photocatalytic performance of the $\mathrm{FTO} / \mathrm{TiO}_{2} /$ porphyrin/ $/ \mathrm{IO}_{2}$ photoanodes to two factors: a slow electron injection into $\mathrm{TiO}_{2}$ and a weak cross-surface hole transport between photosensitizers (respectively the steps (i) and (iii) in Fig. 14(A)).

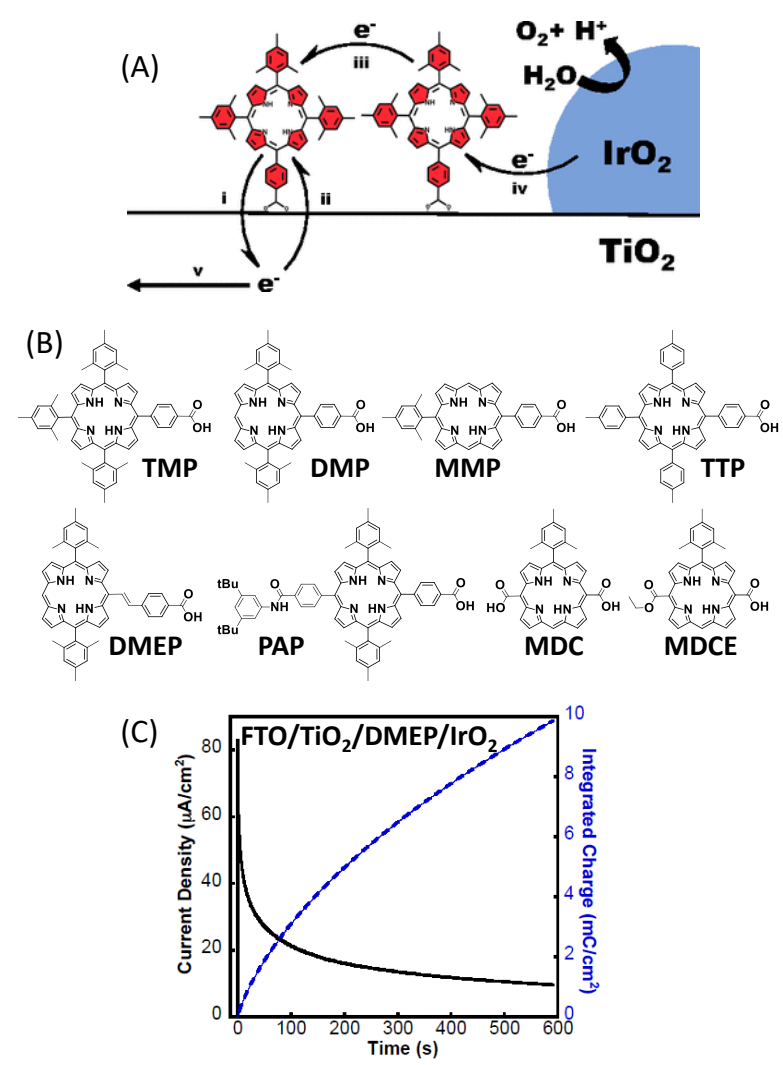

Fig. 14. (A) Schematic representation of the $\mathrm{FTO} / \mathrm{TiO}_{2} /$ porphyrin//rO photoanode developed by Mallouk and coworkers ${ }^{51}$; the five steps of electron transfer process in such water-splitting DS-PEC are: (i) electron injection, (ii) charge recombination, (iii) hole transfer, (iv) regeneration of the neutral photosensitizer and (v) electron transport to the FTO electrode. (B) Series of free-base porphyrins to implement hybrid photoanodes. (C) Representative photocurrent density and integrated charge in function of time for a $\mathrm{FTO} / \mathrm{TiO}_{2} / \mathrm{DMEP} / \mathrm{IrO}_{2}$ photoanode under illumination at $\lambda \geq 410$ $\mathrm{nm}$ in phosphate buffer at $\mathrm{pH} 6.8$ under an applied potential of $+0.1 \mathrm{~V}$ vs $\mathrm{Ag} / \mathrm{AgCl}$, and associated to a platinum mesh counter electrode (reproduced from ref $^{51}$, with the permission from the National Academy of Sciences of the United states of America, Copyright 2015). 
Short circuit absorbed photon-to-current efficiency (APCE) measurements, recorded with $\mathrm{FTO} / \mathrm{TiO}_{2} /$ dye (without $/ \mathrm{IO}_{2}$ catalyst) and within the first milliseconds of illumination, demonstrated that the light-driven electron injection from porphyrin dyes into $\mathrm{TiO}_{2}$ is much less efficient than that from the Ru dye, with APCE values between 2.4 and $7.4 \%$ for porphyrins and of $20.9 \%$ for the Ru dye. The weak electron injection into the semiconducting electrode is at the origin of a poor photocurrent during photocatalysis. Another factor ruling the generation of photocurrent is the efficiency of the hole transport at the surface of $\mathrm{TiO}_{2}$, that requires a great crosssurface electron diffusion coefficient $\left(D_{\text {app }}\right)$ of the photosensitizer and a slow charge recombination (associated to the time constant $\tau_{\mathrm{r}}$ ) between the holes on the oxidized dye and the electrons within the $\mathrm{CB}$ of $\mathrm{TiO}_{2}$. In spite of the fact that the porphyrins on $\mathrm{TiO}_{2}$ display slower charge recombinations $\left(25<\tau_{\mathrm{r}}<59 \mathrm{~ms}\right)$ than that of Ru dye $(4 \mathrm{~ms})$ and surface coverages $\left(0.42 \times 10^{-7}<\Gamma<2.8 \times 10^{-7} \mathrm{~mol}\right.$ $\left.\mathrm{cm}^{-2}\right)$ similar to that of Ru dye $\left(1 \times 10^{-7} \mathrm{~mol} \mathrm{~cm}{ }^{-2}\right)$, the hole transport over the surface with porphyrins remains inefficient with low $D_{a p p}$ values $\left(<10^{-11} \mathrm{~cm}^{2} \mathrm{~s}^{-1}\right)$. $D_{\text {app }}$ values of porphyrin dyes are clearly inferior to those of Ru polypyridyl dyes which generally show values between $10^{-9}$ and $10^{-11} \mathrm{~cm}^{2} \mathrm{~s}^{-1}$ and slightly higher photocurrents (see above) when they are deposited on $\mathrm{TiO}_{2}$.

In summary, as for the $\pi$-conjugated polymer DS-PEC published by Sivula, ${ }^{64}$ these hybrid photoanodes sensitized with free base porphyrins do not exhibit significant photocurrents $\left(<40 \mu \mathrm{A} \mathrm{cm}{ }^{-2}\right)$ and present a poor stability over time. Nevertheless, the latter open new perspectives to implement efficient photoelectrochemical water-splitting devices, since they can use red light to drive watersplitting reaction, thereby extending the absorption of the device across the solar spectrum which could significantly improve the overall energy conversion efficiency.

\section{Summary and outlook}

This review refers to the few examples of hybrid photoanodes reported for light-driven water oxidation which are based on a $n$ type semiconducting electrode sensitized by a molecular dye in association with a metal oxide as water oxidation catalyst. Since the introduction of the first example published by Mallouk in 2009, based on a $\mathrm{TiO}_{2} /$ trisbipyridine $\mathrm{Ru}-\mathrm{IrO}_{\mathrm{x}}$, efforts have been devoted to re-design the photoanodes in view to improve the photocatalytic performance as well as to implement more earth abundant elements, by substituting the polypyridyl Ru photosensitizers by metal-free organic dyes and the iridium oxide catalyst by cobalt oxide.

All these hybrid photoanodes are active in neutral or weakly acidic medium, demonstrating their potential for the water oxidation reaction. However, they still suffer from low stability over time under photocatalytic conditions (limited to few hours in the best case) and exhibit fairly low photocurrents $\left(10-200 \mu \mathrm{A} \mathrm{cm}{ }^{-2}\right.$; Table 1). The relatively modest photocurrents have been mainly attributed to the poor hole diffusion on the SC surface through PSs and the fast kinetics of back electron transfer (essentially the charge recombination between PS and SC), which competes effectively with the slow electron transfer kinetics between the oxidized PS and the inorganic metal oxide catalyst and the slow catalytic oxidation of water. It is worth noting that the intensity of the photocurrent depends on the bias applied. It is therefore difficult to really compare the performance of the different photoanodes because they are not evaluated at the same bias. The bias can vary from $0.55 \mathrm{~V}$ to $1.61 \mathrm{~V}$ vs RHE which corresponds to an overpotential varying between $-0.68 \mathrm{~V}$ and $0.38 \mathrm{~V}$.

Various strategies have been investigated to improve the photocatalytic performance (photocurrent and stability) of $\mathrm{TiO}_{2} / \mathrm{Ru} / \mathrm{IrO}_{\mathrm{x}}$ hybrid photoanodes. Among these, the addition of a redox mediator to accelerate the electron transfer between the oxidized $\mathrm{Ru}$ dye and $\mathrm{IrO}_{\mathrm{x}}$ and the introduction of a thin insulating layer of metal oxide $\left(\mathrm{ZrO}_{2}\right.$ or $\left.\mathrm{Nb}_{2} \mathrm{O}_{5}\right)$ between $\mathrm{Ru}$ dye and $\mathrm{TiO}_{2}$ to slow down the back electron transfer, were not successful. The approach that considerably increased the photocurrent (by a factor of 2.7) was to deposit a thin layer of $\mathrm{TiO}_{2}$ onto a nanostructured ITO film coated onto FTO electrode, in view to promote a fast electron transport through $\mathrm{TiO}_{2}$ to NanolTO and decrease the charge recombination between the $\mathrm{Ru}$ dye and $\mathrm{TiO}_{2}$. Nevertheless, the photocurrent was unstable once again owing to the PS release from the SC surface by hydrolysis of the anchoring groups. To avoid this PS release, a very thin layer of $\mathrm{TiO}_{2}$ was deposited on the Ru dyes, before the deposition of $\operatorname{IrO}_{x}$ particles, resulting in a stable photocurrent of $100 \mu \mathrm{A} \mathrm{cm}^{-2}$ over $2 \mathrm{~h}$.

In addition to the detachment or degradation of the PS, the decline of the photocurrent for such Ru-based photoanodes was also ascribed to the drop of $\mathrm{pH}$ at the photoanode surface induced by the accumulation of protons (under acidic or neutral conditions) or the consumption of hydroxide anions (under basic conditions) during the photo-oxidation of water. The acidification of the medium close to the surface imposes a positive shift of the standard potential of water oxidation, resulting in a decrease of photocurrent at a fixed bias. In view to display a sustained and high photocurrent, the future hybrid photoanodes should be able to maintain a neutral or basic $\mathrm{pH}$ in proximity to the electrode surface.

Regarding the non-noble metal based photoanodes, the Beranek's group designed effective and stable hybrid photoanodes using a robust organic polymer film, polyheptazine, to photosensitize a $\mathrm{TiO}_{2}$ electrode. Combined with a metal oxide catalyst as $\mathrm{IrO}_{2}$, Co-Pi or $\mathrm{CoO}(\mathrm{OH})_{x}$ particles, relatively high photocurrents (above $100 \mu \mathrm{A} \mathrm{cm}{ }^{-2}$ ) were obtained along with a relatively good stability (until 4 hours) compared to the other hybrid photoanodes reviewed herein. This promising performance could be related to the robustness of polyheptazine and the good hole mobility within this conjugated polymer which competes effectively with the charge recombination between oxidized polyheptazine and $\mathrm{TiO}_{2}$. This work paves the way for the development of new robust and highly efficient photoanodes devoted to water oxidation employing conjugated polymer as photosensitizer. 
Otherwise, it should be stressed that in most of these published water-splitting PECs examples, the amount of photosensitizers and metal oxide catalysts deposited at the surface of the electrodes are weak and not well-controlled. Photosensitizers are generally adsorbed in a monolayer and the amount of catalyst rarely evaluated. To go one step further, it will be very interesting to explore novel methods of fabrication and deposition of photosensitizers/metal oxide nanoparticles on the semi-conducting electrodes in view to evaluate the effect of the amount and the $\mathrm{PS} / \mathrm{MO}_{x}$ ratio of deposited material and of its nano-structuration on the performance of the photoanodes (i.e. intensity of the catalytic photocurrent and stability). In this line, a strategy could be to entrap photosensitizers and metal oxide particles into a polymer matrix, by controlling the formation and the size of the particles and the amount of the photosensitizer deposited. The polymer matrix will promote the stability of the $\mathrm{MO}_{\mathrm{x}}$ particles by precluding their corrosion during photocatalysis. ${ }^{82,83}$ Our group recently reported such nanostructured material electrogenerated at the surface for a hybrid photocathode for water reduction into $\mathrm{H}_{2}$ based on a polypyrrole film of Ru tris-bipyridine containing MoS $_{x}$ NPs. ${ }^{41}$ This photosensitive material, which strongly absorbs the visible light due to its thick layer of the Ru dye, exhibits a significant photocatalytic activity owing to the high PS/Cat ratio of 2 and the small $(60 \mathrm{~nm})$ and non-agglomerated MoS $_{x}$ particles, which confer a large catalytically active surface area. Such strategy could be implemented to the preparation of efficient hybrid photoanodes for water oxidation.

Regarding the photosensitizers, the published examples of hybrid photoanodes for water oxidation already employed the main families of molecular photosensitizers with adequate absorption, photophysical and redox properties to promote visible-light water oxidation through a metal oxide catalyst. If other dyes families potentially more resistant to the degradation in aqueous media have to be explored in view to improve the global stability of the photoelectrodes, the bottleneck of these hydrid photoanodes is not so much the dye, but rather the slow kinetics and high overpotential of the oxidation of water. Up to now, only three families of metal oxides $\left(\mathrm{IrO}_{2}\right.$, Co-Pi or $\left.\mathrm{CoO}(\mathrm{OH})_{\mathrm{x}}\right)$ have been tested while plenty of inorganic OER catalysts with lower overpotentials have been reported the last decades such as, for example, alloys of $\mathrm{NiFeO}_{\mathrm{x}}$ or $\mathrm{CoFeO}_{\mathrm{x}}{ }^{45,84,85}$ Using such inorganic OER catalysts with lower overpotentials should be another way to significantly improve the performance of the hybrid photoanodes.

Finally, these hybrid photoanodes could be also used to drive photo-induced oxidation of organic or inorganic substrates, as alternative to OER, within PEC cell geared toward $\mathrm{H}_{2}$ production. Basically, OER, the bottleneck of water splitting reaction, could be replaced by more kinetically facile oxidation of organic (e.g. 2,5hydroxymethylfurfural (HMF)) or halide substrates (e.g. chloride) to produce more valorized chemicals than $\mathrm{O}_{2}$ (respectively 2,5 difuran carboxylic acid (FDCA) and $\mathrm{Cl}_{2}$ gas). ${ }^{86}$ Since metal oxide materials have been identify as catalysts for the oxidation of alternate substrates, ${ }^{86}$ the use of hybrid photoanodes combining metal oxide

catalysts and molecular PSs would enable to define new paradigms for solar-driven organic chemistry, and to access to new PECS cleanly producing $\mathrm{H}_{2}$ at the photocathode and value-added chemicals at the photoanode from cheap and renewable feedstocks.

\section{Conflicts of interest}

There are no conflicts to declare.

\section{Acknowledgements}

Becas-Chile (Conicyt) "Programa de formación de capital humano avanzado" for the PhD fellowship of DVM $\left(\mathrm{N}^{\circ}\right.$ 72150091) and CAN ( $N^{\circ}$ 72170399), the ECOS-CONICYT exchange program (C13E01), and the COST CM1202 program (PERSPECT $\mathrm{H}_{2} \mathrm{O}$ ). This work has been partially supported by Labex Arcane and CBH-EUR-GS (ANR-17-EURE-0003).

\section{Notes and references}

1

2
A. J. Bard and M. A. Fox, Acc. Chem. Res., 1995, 28, 141. M. G. Walter, E. L. Warren, J. R. McKone, S. W. Boettcher, Q. Mi, E. A. Santori and N. S. Lewis, Chem. Rev., 2010, 110, 6446.

E. S. Andreiadis, M. Chavarot-Kerlidou, M. Fontecave and V. Artero, Photochem. Photobiol., 2011, 87, 946.

J. R. Swierk and T. E. Mallouk, Chem. Soc. Rev., 2013, 42, 2357.

F. E. Osterloh, Chem. Soc. Rev., 2013, 42, 2294.

K. S. Joya, Y. F. Joya, K. Ocakoglu and R. van de Krol, Angew. Chem. Int. Ed., 2013, 52, 10426.

M. S. Prévot and K. Sivula, J. Phys. Chem. C, 2013, 117, 17879.

J. R. McKone, N. S. Lewis and H. B. Gray, Chem. Mater., 2014, 26, 407.

Z. Yu, F. Li and L. Sun, Energy Environ. Sci., 2015, 8, 760.

N. Queyriaux, N. Kaeffer, A. Morozan, M. ChavarotKerlidou and V. Artero, J. Photochem. Photobiol. C: Photochem. Rev., 2015, 25, 90.

K. Sivula and R. van de Krol, Nat. Rev. Mats., 2016, 1, 15010.

I. Roger, M. A. Shipman and M. D. Symes, Nat. Rev. Chem., 2017, 1, 0003.

J. T. Kirner and R. G. Finke, J. Mater. Chem. A, 2017, 5, 19560.

P. Xu, N. S. McCool and T. E. Mallouk, Nano Today, 2017, $14,42$.

A. Eftekhari, V. J. Babu and S. Ramakrishna, Int. J. Hydrogen Energy, 2017, 42, 11078.

A. Fujishima and K. Honda, Nature, 1972, 238, 37.

T. Bosserez, J. Rongé, J. van Humbeeck, S. Haussener and J. Martens, Oil Gas Sci. Technol. - Rev. IFP Energies nouvelles, 2015, 70, 877.

M. Crespo-Quesada and E. Reisner, Energy Environ. Sci., 2017, 10, 1116.

M. F. Weber and M. J. Dignam, J. Electrochem. Soc., 1984, 131, 1258. 
L. L. Gao, F. Li, H. G. Hu, X. F. Long, N. Xu, Y. P. Hu, S. Q. Wei, C. L. Wang, J. T. Ma and J. Jin, Chemsuschem, 2018, 11, 2502.

F. Li, J. Li, L. Gao, Y. Hu, X. Long, S. Wei, C. Wang, J. Jin and J. Ma, J. Mater. Chem. A, 2018, 6, 23478.

C. Wang, X. Long, S. Wei, T. Wang, F. Li, L. Gao, Y. Hu, S. Li and J. Jin, ACS Appl. Mater. Interfaces, 2019, 11, 29799.

L. Gao, X. Long, S. Wei, C. Wang, T. Wang, F. Li, Y. Hu, J. Ma and J. Jin, Chem. Eng. J., 2019, 378, 122193.

N. Xu, F. Li, L. Gao, H. Hu, Y. Hu, X. Long, J. Ma and J. Jin, Int. J. Hydrogen Energy, 2018, 43, 2064.

Z. Zou, J. Ye, K. Sayama and H. Arakawa, Nature, 2001, 414, 625.

R. Asahi, T. Morikawa, T. Ohwaki, K. Aoki and Y. Taga, Science, 2001, 293, 269.

A. Kasahara, K. Nukumizu, T. Takata, J. N. Kondo, M. Hara, H. Kobayashi and K. Domen, J. Phys. Chem. B, 2003, 107, 791.

A. Kasahara, K. Nukumizu, G. Hitoki, T. Takata, J. N. Kondo, M. Hara, H. Kobayashi and K. Domen, J. Phys. Chem. A, 2002, 106, 6750.

D. Yokoyama, T. Minegishi, K. Maeda, M. Katayama, J. Kubota, A. Yamada, M. Konagai and K. Domen, Electrochem. Commun., 2010, 12, 851.

K. Ohashi, K. Uosaki and J. O. Bockris, Int. J. Energy Res., 1977, 1, 25.

W. Siripala, A. Ivanovskaya, T. F. Jaramillo, S.-H. Baeck and E. W. McFarland, Sol. Energy Mater. Sol. Cells, 2003, 77, 229.

A. Paracchino, V. Laporte, K. Sivula, M. Grätzel and E. Thimsen, Nat. Mater., 2011, 10, 456.

A. Paracchino, N. Mathews, T. Hisatomi, M. Stefik, S. D. Tilley and M. Grätzel, Energy Environ. Sci., 2012, 5, 8673.

C.-Y. Lin, Y.-H. Lai, D. Mersch and E. Reisner, Chem. Sci., 2012, 3, 3482.

E. Aharon-Shalom and A. Heller, J. Electrochem. Soc., 1982, 129, 2865.

O. Khaselev and J. A. Turner, Science, 1998, 280, 425.

S. Licht, B. Wang, S. Mukerji, T. Soga, M. Umeno and H. Tributsch, Int. J. Hydrogen Energy, 2001, 26, 653.

E. Verlage, S. Hu, R. Liu, R. J. R. Jones, K. Sun, C. Xiang, N. S. Lewis and H. A. Atwater, Energy Environ. Sci., 2015, 8, 3166.

W. J. Youngblood, S.-H. A. Lee, K. Maeda and T. E. Mallouk, Acc. Chem. Res., 2009, 42, 1966.

H.-L. Wu, X.-B. Li, C.-H. Tung and L.-Z. Wu, Adv. Sci., 2018, 5, 1700684.

Y. Lattach, J. Fortage, A. Deronzier and J.-C. Moutet, ACS Appl. Mater. Interfaces, 2015, 7, 4476.

C. E. Castillo, M. Gennari, T. Stoll, J. Fortage, A. Deronzier, M. N. Collomb, M. Sandroni, F. Légalité, E. Blart, Y. Pellegrin, C. Delacote, M. Boujtita, F. Odobel, P. Rannou and S. Sadki, J. Phys. Chem. C, 2015, 119, 5806.

M. Grätzel, Acc. Chem. Res., 2009, 42, 1788.

M. K. Brennaman, R. J. Dillon, L. Alibabaei, M. K. Gish, C. J. Dares, D. L. Ashford, R. L. House, G. J. Meyer, J. M. Papanikolas and T. J. Meyer, J. Am. Chem. Soc., 2016, 138, 13085.

N.-T. Suen, S.-F. Hung, Q. Quan, N. Zhang, Y.-J. Xu and H. M. Chen, Chem. Soc. Rev., 2017, 46, 337.

W. J. Youngblood, S. H. A. Lee, Y. Kobayashi, E. A. Hernandez-Pagan, P. G. Hoertz, T. A. Moore, A. L. Moore,
D. Gust and T. E. Mallouk, J. Am. Chem. Soc., 2009, 131, 926.

47 S.-H. A. Lee, Y. Zhao, E. A. Hernandez-Pagan, L. Blasdel, W. J. Youngblood and T. E. Mallouk, Faraday Discuss., 2012, 155, 165.

48 Y. Zhao, J. R. Swierk, J. D. Megiatto, B. Sherman, W. J. Youngblood, D. Qin, D. M. Lentz, A. L. Moore, T. A. Moore, D. Gust and T. E. Mallouk, Proc. Natl. Acad. Sci. USA, 2012, 109, 15612.

J. R. Swierk, N. S. McCool, T. P. Saunders, G. D. Barber and T. E. Mallouk, J. Am. Chem. Soc., 2014, 136, 10974.

J. R. Swierk, N. S. McCool, T. P. Saunders, G. D. Barber, M. E. Strayer, N. M. Vargas-Barbosa and T. E. Mallouk, J. Phys. Chem. C, 2014, 118, 17046.

51 J. R. Swierk, D. D. Méndez-Hernández, N. S. McCool, P. Liddell, Y. Terazono, I. Pahk, J. J. Tomlin, N. V. Oster, T. A. Moore, A. L. Moore, D. Gust and T. E. Mallouk, Proc. Natl. Acad. Sci. USA, 2015, 112, 1681.

K. E. Michaux, A. A. Gambardella, L. Alibabaei, D. L. Ashford, B. D. Sherman, R. A. Binstead, T. J. Meyer and R. W. Murray, J. Phys. Chem. C, 2015, 119, 17023. P. Wei, B. Hu, L. Zhou, T. Su and Y. Na, J. Energy Chem., 2016, 25, 345.

54 M. Bledowski, L. Wang, A. Ramakrishnan, O. V. Khavryuchenko, V. D. Khavryuchenko, P. C. Ricci, J. Strunk, T. Cremer, C. Kolbeck and R. Beranek, Phys. Chem. Chem. Phys., 2011, 13, 21511.

L. Wang, M. Bledowski, A. Ramakrishnan, D. König, A. Ludwig and R. Beranek, J. Electrochem. Soc., 2012, 159, H616.

56 M. Bledowski, L. Wang, A. Ramakrishnan and R. Beranek, MRS Proceedings, 2012, 1442, mrss 12.

M. Bledowski, L. Wang, A. Ramakrishnan, A. Bétard, O. V. Khavryuchenko and R. Beranek, ChemPhysChem, 2012, 13, 3018.

M. Bledowski, L. Wang, A. Ramakrishnan and R. Beranek, J. Mater. Res., 2013, 28, 411.

O. V. Khavryuchenko, L. Wang, D. Mitoraj, G. H. Peslherbe and R. Beranek, J. Coord. Chem., 2015, 68, 3317.

60 L. Wang, D. Mitoraj, S. Turner, O. V. Khavryuchenko, T. Jacob, R. K. Hocking and R. Beranek, ACS Catal., 2017, 7, 4759.

61 J. T. Kirner, J. J. Stracke, B. A. Gregg and R. G. Finke, ACS Appl. Mater. Interfaces, 2014, 6, 13367.

62 J. T. Kirner and R. G. Finke, ACS Appl. Mater. Interfaces, 2017, 9, 27625.

F. Ronconi, Z. Syrgiannis, A. Bonasera, M. Prato, R. Argazzi, S. Caramori, V. Cristino and C. A. Bignozzi, J. Am. Chem. Soc., 2015, 137, 4630.

64 P. Bornoz, M. S. Prévot, X. Yu, N. Guijarro and K. Sivula, J. Am. Chem. Soc., 2015, 137, 15338.

65 A. Harriman, I. J. Pickering, J. M. Thomas and P. A. Christensen, J. Chem. Soc. Faraday Trans. I, 1988, 84, 2795.

A. Kay and M. Grätzel, Chem. Mater., 2002, 14, 2930.

E. Palomares, J. N. Clifford, S. A. Haque, T. Lutz and J. R. Durrant, J. Am. Chem. Soc., 2003, 125, 475.

68 W. L. Hoffeditz, M. J. Pellin, O. K. Farha and J. T. Hupp, Langmuir, 2017, 33, 9298.

69 R. Beranek, Adv. Phys. Chem., 2011, 2011, 20.

70 K. Kalyanasundaram and M. Grätzel, Coord. Chem. Rev., 1998, 177, 347. 
B. Gerey, E. Gouré, J. Fortage, J. Pécaut and M.-N. Collomb, Coord. Chem. Rev., 2016, 319, 1.

J. R. Swierk, N. S. McCool and T. E. Mallouk, J. Phys. Chem. C, 2015, 119, 13858.

Z. Huang, Y. V. Geletii, D. Wu, C. L. Anfuso, D. G. Musaev, C. L. Hill and T. Lian, Tachibana, Y., Ed.; SPIE: Bellingham, WA, 2011, 8109, 810903.

J. B. Asbury, Y.-Q. Wang, E. Hao, H. N. Ghosh and T. Lian, Res. Chem. Intermed., 2001, 27, 393.

M. W. Kanan and D. G. Nocera, Science, 2008, 321, 1072.

Y. Surendranath, M. Dinca and D. G. Nocera, J. Am. Chem. Soc., 2009, 131, 2615.

M. W. Kanan, Y. Surendranath and D. G. Nocera, Chem. Soc. Rev., 2009, 38, 109.

Y. Surendranath, D. A. Lutterman, Y. Liu and D. G. Nocera, J. Am. Chem. Soc., 2012, 134, 6326.

S. K. Lee, Y. Zu, A. Herrmann, Y. Geerts, K. Müllen and A. J. Bard, J. Am. Chem. Soc., 1999, 121, 3513.

E. M. P. Steinmiller and K.-S. Choi, Proc. Natl. Acad. Sci. USA, 2009, 106, 20633.

B. D. Sherman, M. V. Sheridan, C. J. Dares and T. J. Meyer, Anal. Chem., 2016, 88, 7076.

Z. B. Shifrina, V. G. Matveeva and L. M. Bronstein, Chem. Rev., 2019, DOI: 10.1021/acs.chemrev.9b00137.

D. V. Morales, C. N. Astudillo, Y. Lattach, B. F. Urbano, E. Pereira, B. L. Rivas, J. Arnaud, J.-L. Putaux, S. Sirach, S. Cobo, J.-C. Moutet, M.-N. Collomb and J. Fortage, Catal. Sci. Technol., 2018, 8, 4030.

D. Friebel, M. W. Louie, M. Bajdich, K. E. Sanwald, Y. Cai, A. M. Wise, M.-J. Cheng, D. Sokaras, T.-C. Weng, R. Alonso-Mori, R. C. Davis, J. R. Bargar, J. K. Nørskov, A. Nilsson and A. T. Bell, J. Am. Chem. Soc., 2015, 137, 1305. M. S. Burke, L. J. Enman, A. S. Batchellor, S. Zou and S. W. Boettcher, Chem. Mater., 2015, 27, 7549.

C. R. Lhermitte and K. Sivula, ACS Catal., 2019, 9, 2007. 


\section{Table of Content Entry}

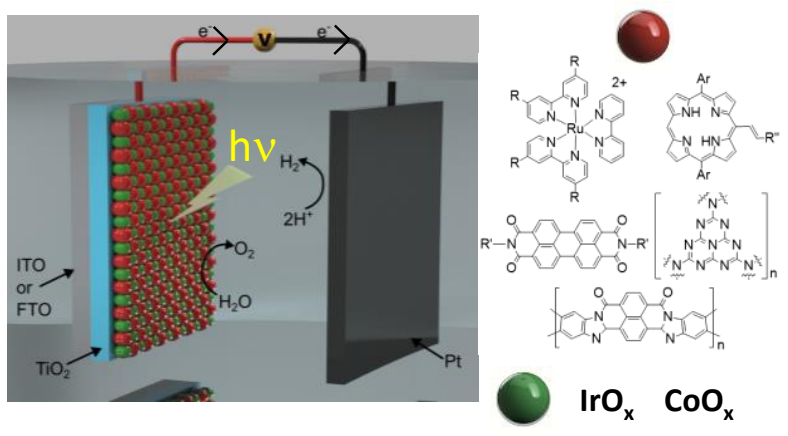

Hybrid photoanodes for water oxidation, using a $n$ semiconductor photosensitized by a molecular dye associated with an inorganic catalyst, are overviewed 